\title{
The risks and outcomes of getting help for marginalised people: navigating access to social assistance in crises
}

Brigitte Rohwerder and Carolina Szyp

BASIC Research

October 2022

Implemented by

institute of development studies 


\section{Summary}

Crises exacerbate existing inequalities and vulnerabilities for marginalised people, including women and girls, children and youth, older people, people with disabilities, ethnic and religious minorities, and sexual and gender minorities. Many of them face multiple and intersecting inequalities, especially people who are forcibly displaced. Social assistance seeks to alleviate crisis impacts by protecting vulnerable people and averting them from deprivation, but the same structures and systems that make some people more exposed (and excluded) generally can exclude them from social assistance in crises and further undermine their situation. There is substantial literature that already discusses the benefits and opportunities of social assistance generally. The added value of this paper is in examining the risks of navigating access to social assistance in crises for these marginalised people, and the positive and negative outcomes of accessing or not accessing this assistance. The existing evidence suggests that social assistance can improve marginalised people's food security, help households meet their basic needs, reduce stress and household tensions, reduce gender-based violence, improve health, education, and wellbeing, and reduce negative coping mechanisms. However, it can also disrupt their social support mechanisms and expose them to violence and further risks. Such risks - some of which also apply to those who are excluded from social assistance, and which do not apply to all marginalised people all the time similarly - include neglect, discrimination, sexual exploitation and abuse, increased household and community tensions, gender-based violence, stigma, theft, and accessibility issues.

\section{About the authors}

Brigitte Rohwerder is a Research Officer based at the Institute of Development Studies (IDS), in the Participation, Inclusion and Social Change Cluster. She currently works mainly on supporting research and learning in Inclusion Works and Disability Inclusive Development - two disability inclusion programmes funded by the United Kingdom (UK) Foreign, Commonwealth \& Development Office (FCDO) and implemented through consortiums led by Sightsavers. She has a background in disability inclusion, conflict, and humanitarian response.

Carolina Szyp is a Research Officer at IDS. Her research experience and interests include youth livelihoods, decent work, education, and social protection. Since joining IDS, she has worked on a number of projects looking at how children and young people engage with the rural economy and education and focusing on the impact of social protection interventions on youth employment outcomes. 


\section{Contents}

1. Introduction $\quad 5$

1.1 Crises and social assistance $\quad 5$

1.2 The importance of focusing on marginalised people in crises 5

1.2.1 Marginalisation and social exclusion 5

1.3 Focus of the paper $\quad 6$

$\begin{array}{ll}\text { 1.3.1 Methods } & 7\end{array}$

1.4 Structure $\quad 7$

1.5 Note on vulnerability $\quad 7$

2. Social assistance in crises for marginalised people $\quad 8$

2.1 The importance of context for the experience of social assistance 8

2.2 Intersectionality 8

2.3 Risks of navigating access to social assistance for marginalised people 9

2.3.1 Pre-distribution 9

2.3.2 Distribution $\quad 12$

2.3.3 Post-distribution 14

2.3.4 Outcomes of not receiving social assistance for marginalised people $\quad 15$

2.3.5 Outcomes of receiving social assistance for marginalised people 16

3. Women and girls 20

$\begin{array}{ll}3.1 \text { Needs } & 20\end{array}$

3.2 Risks 21

3.2.1 Pre-distribution $\quad 21$

3.2.2 Distribution 21

3.2.3 Post-distribution 22

3.3 Outcomes 22

4. Children and adolescents $\quad 24$

4.1 Children, adolescents and youth: classification challenges 24

4.2 Needs 25

4.3 Risks 25

4.4 Outcomes 26

5. Youth 28

5.1 Needs $\quad 28$

5.2 Risks 28

5.3 Outcomes 29

6. Older people $\quad 30$

6.1 Needs $\quad 30$

6.2 Risks 31

6.2.1 Pre-distribution 31 
6.2.2 Distribution 31

6.2.3 Post-distribution 31

6.3 Outcomes 32

7. People with disabilities 32

7.1 Needs 32

7.2 Risks 33

7.2.1 Pre-distribution 33

7.2.2 Distribution 33

7.2.3 Post-distribution 34

7.3 Outcomes 34

8. Ethnic and religious minorities

8.1 Ethnic and religious minorities: classification challenges 34

8.2 Needs 35

8.3 Risks 35

8.4 Outcomes 36

9. Sexual and gender minorities $\quad 37$

$\begin{array}{ll}9.1 \text { Needs } & 37\end{array}$

9.2 Risks $\quad 38$

9.3 Outcomes 39

10. Analysis $\quad 40$

11. Conclusions $\quad 43$

Potential research questions for BASIC Research

$\begin{array}{ll}\text { References } & 45\end{array}$ 


\section{Introduction}

\subsection{Crises and social assistance}

Crises, such as protracted conflict, forced displacement, and recurrent climate shocks (which increase the likelihood of natural disasters), disrupt people's lives and can deprive them of access to food, adequate shelter, and other basic needs. Social assistance seeks to alleviate these effects by protecting people and averting them from deprivation (Freccero et al. 2019: 696; Slater and Sabates-Wheeler 2021: 4). Social assistance is narrower than social protection and includes social transfers (cash, vouchers, food, and nonfood items), public works programmes, fee waivers, and subsidies (Slater and Sabates-Wheeler 2021: 2). Whereas the provision of social assistance is often associated with state systems, social assistance in crises also includes humanitarian assistance, which uses the same modalities (cash, vouchers, food aid, non-food items, and public works), and is guided by core humanitarian principles of neutrality, independence, and impartiality (Good Humanitarian Donorship (GHD) 2003; Slater and Sabates-Wheeler 2021: 5). This means that in some contexts, particularly conflict contexts, humanitarian assistance substitutes for states that are unable to support their citizens (Slater and Sabates-Wheeler 2021). Social assistance, as defined above, is the focal point of this paper (where evidence was found), but also, if and where particularly relevant, we pick up on examples of assistance that look beyond these modalities to wider instruments - including some that might not be defined as social assistance but could be described as 'socially protecting' in contexts of crises (e.g., shelter facilities).

In the context of the Better Assistance in Crises (BASIC) Research programme, crises are defined as contexts where there are overlapping challenges from conflict and violence, climate change, natural disasters, extreme and chronic poverty, displacement, humanitarian crisis, and fragility. Not all countries of interest will necessarily face all these overlapping challenges, or all at the same time. Crises can also be acute, protracted, and/or recurring as well as predictable or unpredictable. Risks can fluctuate over time. The providers of social assistance can change according to the phase of the crisis, which can, in turn, affect the inclusivity of the support provided.

\subsection{The importance of focusing on marginalised people in crises}

\subsubsection{Marginalisation and social exclusion}

The desperate situations people find themselves in during crises leave them vulnerable to exploitation and abuse (Potts et al. 2020a: 17). It is increasingly acknowledged that certain groups of marginalised people are disproportionally impacted by crises and face heightened or compounded risks, including deprivation (GPC Task Team on Cash for Protection 2020: 18; Robinson, Marella and Logam 2020: 8). Social exclusion or marginalisation is 'both a process, and a condition, that prevents individuals or groups from full participation in social, economic and political life' and is a major cause of vulnerability (UK Aid Direct 2017: 1). 'Exclusionary processes can occur at various levels - within and between households, villages, cities, states, and globally' (Barbelet and Wake 2020: 13). Social, economic, and political barriers, and discrimination, all contribute to the exclusion and marginalisation of an individual or group of individuals, and 'people can be marginalised due to multiple factors; sexual orientation, gender, geography, ethnicity, religion, displacement, conflict or disability' (Mannion Daniels 2017: 1). There is also a close connection between social exclusion and poverty (Narayan et al. 2000). It should also be noted that despite sharing some form of group identity, the experiences of women and girls or people with disabilities (for example) can be very diverse, resulting from intersecting identities and discrimination; people do not belong to mono-dimensional marginalised groups with exactly the same shared experiences. Different types of marginalisation can intersect to multiply disadvantage depending on the context and the power asymmetries that exist within groups of excluded individuals (UK Aid Direct 2017; Narayan 2000).

Social exclusion involves at least four factors: the excluded (often as per above factors); the institutions from which they are excluded (social assistance but also other institutions and services); the agents whose actions result in their exclusion; and the processes through which exclusion occurs (Narayan et al. 2000: 229). Power relations are an important element in social exclusion (Narayan et al. 2000). The main mechanisms of social exclusion were identified by Christine Bradley, in order of increasing severity, as: geography (where people live); entry barriers (e.g., transaction costs, documentation requirements, hostility, and unfairness); corruption (connections and bribes); intimidation (psychological violence); and physical violence (Narayan et al. 2000: 230-36). These mechanisms of exclusion are particularly challenging for marginalised people and can often exacerbate inequalities. 
Exclusion from social assistance, both before and during a crisis, can increase deprivation, leave people less resilient to shocks, and exacerbate protection risks by increasing their vulnerability to exploitation and abuse; these are just some of the ways in which marginalised people can be disproportionally affected (Freccero et al. 2019: 696). Social exclusion results from discrimination against individuals due to features of identity such as gender, age, disability, ${ }^{1}$ ethnicity, caste, race, religion, and sexual orientation (Barbelet and Wake 2020: 26). The same structures and systems that make people more vulnerable and exposed generally can leave them marginalised or excluded from social assistance during crises (ibid.). These specific groups of people may face greater barriers to accessing and participating in social assistance programming, or face greater protection risks because of how their gender, age, disability, or other socio-demographic factors can intersect with risk factors (Freccero et al. 2019: 696-708; GPC Task Team on Cash for Protection 2020: 18). Because providers of social assistance can change according to the phase of the crisis, risks, and outcomes of social assistance for marginalised people will also vary. So, for example, people who are marginalised due to their ethnicity or displacement status may face higher levels of discrimination once responsibility for social assistance passes from humanitarian actors to state actors.

The barriers these marginalised people face include 'environmental factors, such as physical, information or communication barriers; attitudinal barriers, such as negative perceptions of certain groups and discrimination; and institutional barriers, such as discriminatory laws, policies, or procedures' (Freccero et al. 2019: 690). Ultimately, these barriers have their roots in social norms that result in negative stereotypes (thoughts), prejudice (feelings), and discrimination (behaviours). These barriers operate at multiple levels and at different stages of the journey through the social assistance system. They can also increase vulnerability to protection risks during crises, including various forms of violence, abuse, discrimination, and exclusion from programming (ibid.). However, this is often not taken into account in social assistance programming during crises, and the inclusion of marginalised people remains an under-prioritised or emerging area of work in crisis contexts (Freccero et al. 2019: 690; Robinson et al. 2020: 8). This can be as a result of a number of factors, as already highlighted; but it should also be noted that with racism, sexism, and ableism present in all societies, government actors and 'humanitarian actors own prejudice plays a part in how they interact with people affected by crisis and the decisions they make', including about access to social assistance (Barbelet and Wake 2020: 29).

It should also be noted that discrimination and exclusion from social assistance on the basis of gender, age, disability, race, or other aspects of social identity are human rights violations in themselves. A variety of legal and normative frameworks exist which underpin non-discrimination and meaningful access in crisis settings. Both international humanitarian law and international human rights law require that people have access to services on an equal basis, with no adverse distinction or discrimination. Other legal and normative frameworks that apply include: the humanitarian principle of impartiality (humanitarian aid must be provided solely on the basis of need, without discrimination); protection mainstreaming principles; Article 11 on situations of risk and humanitarian emergencies of the United Nations (UN) Convention on the Rights of Persons with Disabilities (UNCRPD); and the UN Convention on the Rights of the Child (UNCRC), for example.

\subsection{Focus of the paper}

As a result, the paper takes a closer look at the experiences of these marginalised people, and the risks and positive and negative outcomes that navigating access to social assistance in crises has for them. Drawing on both academic and grey literature it seeks to examine:

- What does getting or not getting social assistance in crises mean for marginalised people?

- What risks do people take in navigating access to social assistance and how are they gendered?

- What evidence is there of positive and negative outcomes from receiving or not receiving social assistance relating to gender, age, disability and other intersecting vulnerabilities?

The paper looks at these risks and outcomes across the social assistance programme cycle: pre-distribution, during distribution, and post-distribution.

\footnotetext{
${ }^{1}$ A note on the use of language about disability. The use of 'people with disabilities' or 'persons with disabilities' is known as person-first language, affirming the person before the impairment or disability. It is the preferred term in many countries. In other countries, such as the United Kingdom (UK), the preferred term is 'disabled people', acknowledging that people are disabled by a variety of barriers in exclusionary and inaccessible environments. This paper uses the terms 'people with disabilities' and 'disabled people' interchangeably.
} 


\subsubsection{Methods}

Searches were made across academic databases and Google to capture academic papers and grey literature for each of the different groups and terms relating to social assistance in crises. Additional papers were found through snowballing, as well as from public Zotero libraries created by BASIC Research ${ }^{2}$, and private libraries belonging to BASIC SPACE and BASIC Technical Assistance Services (TAS). These searches looked at each of the individual groups of marginalised people together with each of the different social assistance modalities in crises (e.g. older people AND cash assistance AND crises). Time constraints meant that these searches and the review of the literature was the start of the process of looking at marginalised people's experiences of navigating access to social assistance in crises, but the searches were not by any means systematic nor exhaustive. More literature is available than could be included within the scope and limitations of this paper, although the topic is an under-explored area and the evidence emerging.

As outlined in more detail in the analysis section, our searches found more evidence from humanitarian assistance rather than government-led social assistance in crises contexts, especially contexts involving an element of conflict, natural disasters or displacement. The most common modality of focus found in the papers was cash. We found more evidence relating to the experiences of navigating access to social assistance in crises of women and girls, and children and youth than on the experiences of other marginalised people. The type of evidence identified was a mix of qualitative and quantitative research and programme evaluations. Much is still unknown about this under-explored area. Basic measures, such as data disaggregation, are not routinely undertaken, making it harder to understand different groups' experiences of social assistance.

\subsection{Structure}

This paper is organised as follows. After the introduction, the paper provides an overview of social assistance in crises for marginalised people in general. This draws on examples from the variety of different groups of people the paper focuses on and looks at the risks of navigating access to social assistance for marginalised people pre-distribution, during distribution, and post-distribution, before looking at the outcomes of receiving or not receiving social assistance for these marginalised people.

The paper then focuses on summaries of the literature around gender (which focuses mainly on women and girls), children and adolescents, youth, older people, people with disabilities, ethnic and religious minorities, and sexual and gender minorities. Many of these people have intersecting identities and experience factors such as displacement, which impact on their experiences of navigating access to social assistance in crises. These short summaries consist of looking at these groups' needs, risks and outcomes of navigating access to social assistance and are drawn from longer reviews of literature for these groups of marginalised people which can be found in the annexes of the paper ${ }^{3}$. The paper then analyses the evidence and what it means for the BASIC Research programme, before concluding with some potential research questions.

\subsection{Note on vulnerability}

While the term vulnerability is used in places in this paper, it should be noted that we do not consider this vulnerability to be inherent to the groups of people featured in this paper but rather results from the exclusionary situations they find themselves in (Barbelet and Wake 2020: 25; Hemingway and Priestley 2006: 64). Not all members of these groups are equally vulnerable, nor at the same time during crises, and some will be more vulnerable than others due to the particular protection risks and barriers they face (Barbelet and Wake 2020: 24; Freccero et al. 2019: 711; GPC Task Team on Cash for Protection 2020: 19 21). 'People are, or become, more vulnerable due to an intersecting combination of physical, social, environmental, cultural and political factors, and vulnerability is not a fixed category' (GPC Task Team on Cash for Protection 2020: 18). Barbelet and Wake (2020: 31) note that the way in which vulnerability is operationalised in humanitarian action can be problematic in a number of ways, including 'when it attributes vulnerability according to identities rather than as a consequence of actions and decisions that lead to social exclusion, systematic denial of rights and discrimination' and when it 'ignores the capacities of people affected by crises'.

2 See BASIC Research public Zotero libraries.

3 Annexes are available upon request from $\underline{\text { b.rohwerder@ids.ac.uk. }}$ 


\section{Social assistance in crises for marginalised people}

\subsection{The importance of context for the experience of social assistance}

The different contexts marginalised people find themselves in mediate their experiences of social assistance during crises, as well as affecting their vulnerability to the risks around accessing assistance, pre-distribution, during distribution, and post-distribution.

People's experiences with social assistance during crises are not necessarily consistent or straightforward, with the potential both for positive outcomes (such as relief from deprivation, for example) and negative outcomes (such as increased family and community tensions), as well as risks in the process of receiving assistance (such as sexual exploitation and abuse) (Blackwell et al. 2019; Potts et al. 2020a; Simon 2019). Ensuring these potential positive outcomes and mitigating the potential negative outcomes and risks depends on an understanding of the context people find themselves in and the needs of these marginalised people, as well as designing programmes to mitigate against potential risks (Blackwell et al. 2019; Cross, Manell and Megevand 2018; Simon 2019).

Crises often exacerbate pre-existing inequalities and situations, within the family as well as the wider community, and create new vulnerabilities (Simon 2018). For example, in different contexts, gender norms and attitudes towards women (of any age), especially unaccompanied women, contribute to whether receipt of social assistance is a positive, negative, or mixed experience (Blackwell et al. 2019; Potts et al. 2020b). For example, in Syria, the stigma around women living alone resulted in gossip and exclusion by their neighbours, in the case of widowed or divorced women who were receiving cash assistance (Blackwell et al. 2019). Recent literature highlights the potential of cash to decrease intimate partner violence in development settings (Buller et al. 2018; Cross et al. 2018; Gibbs, Jacobson and Kerr Wilson 2017; Hagen-Zanker et al. 2017), and the positive links between cash and female empowerment/wellbeing, although these are dependent on the programme design and local social norms (Baird et al. 2013; Berg and Seferis 2015; Dickson and Bangpan 2012; International Rescue Committee (IRC) 2016; Özler et al. 2020). Groups with stigmatised identities, such as people with disabilities, children born of wartime rape, or people from sexual and gender minorities, may risk increased stigmatisation if singled out by social assistance programmes (Holden et al. 2019; Neenan 2017; UNHCR 2018). In contexts of crises, where there are often limited resources and increased tensions and desperation, people that are already stigmatised can face increased violence (Freccero et al. 2019; Sheppard, Polack and McGivern 2018). Furthermore, neglected populations, such as older people, often continue to be overlooked (Amnesty International 2020).

\subsection{Intersectionality}

Intersectionality is another important factor to consider. The term was coined in 1989 by Kimberle Crenshaw, who stated that traditional feminist ideas and anti-racist policies in the United States excluded black women because they faced overlapping discrimination that was unique to them (Crenshaw 1989: 140). Intersectionality is a means of 'understanding the interconnectedness of multiple and overlapping systems of discrimination', as a single level of analysis may fail to capture the complex combinations and intersections between power differentials, such as gender or race (Lokot and Avakyan 2020: 42). It means that 'women' or 'disabled people', for example, should not be seen as a homogenous group; rather, there needs to be a recognition that 'intersecting oppressions shape their experiences' (ibid.). For example, an older disabled woman experiences crises and social assistance differently from a young disabled man, despite their both being disabled. Lokot and Avakyan (ibid.) note that 'consideration of power hierarchies more broadly is a significant gap in development and humanitarian agency programming'. Taking into account the power differentials help move beyond seeing groups as vulnerable and aids our understanding of how power, discrimination, and systemic inequalities shape their life experiences. It means not only disaggregating quantitative and qualitative data, but also 'recognising the social and geographical forces shaping people's lives, such as poverty, displacement and conflict' (ibid.).

In this section we outline some similar experiences across the groups of marginalised people featured in this paper, looking first at the risks they face pre-distribution, during distribution, and post-distribution, and then at the outcomes of receiving or not receiving social assistance during crises. 
The subsequent sections focus on specific groups, ${ }^{4}$ although again it should be noted that people do not fit neatly into one group but often span multiple groups, and that the inequalities, needs, risks, and outcomes people across these groups face are often more than the sum of the inequalities of single identifiers. As an initial piece of research, focusing on particular groups helped capture the relevant literature relating to them. Future research may instead take a different approach to incorporate a more intersectional analysis.

\subsection{Risks of navigating access to social assistance for marginalised people}

In this paper, the risks of navigating access to social assistance for marginalised people encompass both the threats and barriers they encounter. The barriers they face increase the risk of adverse distinction, exclusion, or restriction in social assistance programming, contributing to their risk of deprivation; while the threats they face increase the risk of violence, abuse, or exploitation around accessing social assistance. Often, barriers and threats are common to more than one marginalised group; this means that mitigating certain risks can benefit those multiple groups.

However, it should also be noted that these risks do not apply to all marginalised people all the time, and the risks should not be considered to outweigh the potential benefits that social assistance can provide to these marginalised people in crises.

\subsubsection{Pre-distribution}

\section{Lack of inclusive data, knowledge, and understanding by providers}

Lack of knowledge and understanding of specific needs ${ }^{5}$ of different groups can contribute to their exclusion from social assistance programmes. As one study notes:

The experience of individuals in humanitarian crises and their ability to benefit from humanitarian aid are dependent on the programme design's consideration of factors that might influence their ability to access and utilise aid, such as gender dynamics, age, disability status, displacement status, and other intersecting identities.

(Blackwell et al. 2019: 268)

This is furthered by a limited representation of marginalised people among the staff providing social assistance as well as their participation in community-based decision-making structures to inform the design and implementation of this assistance (Bukenya and Yanguas 2013; Golooba-Mutebi 2004). Data disaggregation is not routine, nor does it cover all aspects of a person's identity. However, 'being invisible in data means being invisible in the analysis that underpins the prioritisation of aid and funding' (Barbelet and Wake 2020: 25). Indeed, data disaggregation in preparedness systems such as disaster risk management is key (PAHO 2020), but is often limited, making the response either slow or less appropriate for marginalised people (Heidari, Ahumada and Kurbanova 2020).

The lack of inclusive data and prioritisation of the needs of specific groups in data collection and needs analysis contributes to their marginalisation and neglect by social assistance programming in crises. There are concerns that vulnerable people in communities are not being identified or prioritised for inclusion in social assistance programmes by those compiling eligibility lists (Freccero et al. 2019: 696). Internally displaced persons interviewed in Cameroon and Afghanistan, for example, noted that people they felt should be prioritised for receiving cash (such as widows with many children, orphans, older men and women, people with disabilities, and households with a member who has a chronic illness) were not enrolled in the programme, or if they had been on the list for eligible participants, they had not been selected, even though they were among the most vulnerable in their community (Freccero et al. 2019: 697, 703). Respondents noted that a primary reason for exclusion of eligible vulnerable community members from the list was the lack of sufficient opportunities for registration, resulting in indirect discrimination against certain groups such as

${ }^{4} \mathrm{~A}$ more detailed version of the evidence review for these marginalised people was prepared as an annex and can be supplied upon request to the author.

${ }^{5}$ Here, the term 'specific needs' is not juxtaposed with 'basic needs' and encompasses the requirements of certain groups that enable them to overcome barriers to participation and access. The term 'specific needs' is sometimes contested in the discourse around rights-based approaches to inclusion in humanitarian action, especially by the disability movement. The proximity and sometimes interchangeability of the term 'specific' with 'special' can lead to a false distinction and hierarchy between basic (or essential) needs and specific (or special). This can be then used by actors to deprioritise assistance tailored to meet the requirements of non-dominant social groups. 
those that were working or away from home during registration, or had not yet arrived in the community, and those whose circumstances had since changed for the worse. Respondents further highlighted the inherent challenge of targeting in a context of limited resources where so many people are socioeconomically vulnerable (Freccero et al. 2019: 697).

Even when programmes make an effort to target vulnerable groups, if they do not take those people's needs and capabilities into consideration, this can be problematic, resulting in assistance that is inappropriate (Simon 2018: 11). For example, the categorical targeting of a cash-for-work programme in the Democratic Republic of Congo (DRC) included a large number of elderly and disabled women, but the work was roadbuilding, which was inappropriate for this group of women (Simon 2018: 11; Simon 2019: 21). Simon notes that even with an approach that involves targeting those most in need, 'there is limited information on the successes and challenges of targeting cash-based interventions to the most vulnerable (e.g., femaleheaded households, widows, women with disabilities) in emergency settings' (2019: 21). This lack of clarity about the successes of targeting marginalised people is mainly because the available literature rarely discusses rates of inclusion and exclusion (Simon 2019).

\section{Limited consideration of the politics of social assistance programming}

The politics of programme implementation also need to be understood to better respond to people's experiences of social exclusion. While voice and participation are important elements within development practice, meaningful social accountability cannot rely solely upon participatory mechanisms and must take into account the broader political economy and institutional dynamics at play. Without considering these factors, and without establishing the means to provide adequate and accessible information systems, feedback loops, and monitoring and evaluation procedures, there will be limited scope for individuals, households, and communities to have their needs and priorities heard and responded to (Molyneux, Jones and Samuels 2016).

This is also linked to a demand for stronger social accountability mechanisms in social assistance programmes (Jones et al. 2016). Jones et al.'s (2016) research in Yemen, Palestine, and Mozambique shows that unconditional cash transfer beneficiaries have consistently called for more involvement in programme governance and oversight and wished to be treated with dignity by social assistance programming. For some participants, this involved more accessible information about programme provisions; for others, they wished to improve the communication channels and have more respectful relationships and communications with service providers, while others still proposed embedding mechanisms so that implementers can be better held to account, including for abuses of power (ibid.).

Further information on the institutional and organisational approaches to inclusive social assistance programming can be found in a companion BASIC Research paper by Rachel Slater (forthcoming).

\section{Lack of information about social assistance programming among marginalised people}

Lack of information about programmes can be another barrier to participation in social assistance programming and can contribute to exploitation, as unscrupulous people may suggest they have power over access to assistance and use it to manipulate people who are desperate to access that assistance (Freccero et al. 2019: 708; Potts et al. 2020a). Across different contexts and groups, there are reports that people are unaware of what they are entitled to or the eligibility requirements, which can mean they do not come forward to request assistance. Information may not be conveyed in accessible ways for people with disabilities or may only be produced in a language that is not understood by minority ethnic groups; it may also be that confusion is deliberately caused by those seeking to exploit women's uncertainty as to their entitlements and need for aid (Handicap International 2015; ICRC 2020; Potts et al. 2020b).

This situation is often further exacerbated by a lack of knowledge and understanding among social assistance providers of how to interact and communicate effectively with marginalised people. People with disabilities, for example, often face barriers to informed consent and confidentiality because of dependence (or perceived dependence) on a caregiver. To give another example, women may not be able to speak candidly in front of male relatives. 
In some cases, it can be risky to identify as part of an aid-receiving category when that category is stigmatised - for example, sexual minorities or people with disabilities (Barbelet and Wake 2020: 29; UNHCR 2018). Research carried out by Edge Effect on the impacts of Covid-19 on lesbian, gay, bisexual, transgender, queer, and intersex plus (LGBTQI+) people highlight that in Pakistan, those transgender and other 'visible' individuals, in particular, are fearful to attend public distributions of basic services. In other cases, systematic discrimination or 'gate-keepers' of aid, including officials and community leaders, can hinder distribution of aid to persons with diverse sexual orientation, gender identity and expression, and sex characteristics (SOGIESC) (Edge Effect 2020). Eligibility in targeting of social assistance can be problematic in contexts where social norms often lead to exclusion. For example, targeting women only sets particular barriers for transgender people and gay men (International Gay and Lesbian Human Rights Commission 2011). In some societies, families of people with disabilities have been known to keep them hidden due to the stigma they may face if they are associated with having a disabled family member (Holden et al. 2019: 7). Literature on internal displacement highlights that many internally displaced persons (IDPs) purposely try to stay invisible, and avoid being identified as an IDP, so that they do not lose access to some state-provided social assistance, such as in Nigeria (Olanrewaju et al. 2019).

\section{Corruption, discrimination, and exploitation}

Corruption, stigma, and discrimination, and unscrupulous and exploitative behaviour, can prevent and complicate the experiences of people from marginalised groups in accessing social assistance during crises. In Afghanistan, for example, there were concerns that corruption by village leaders or government officials led to the exclusion of eligible participants (and the inclusion of well-connected people who did not need assistance) (Freccero et al. 2019: 703). Bribery and extortion were also issues for those who were included (or were eligible to be included) on beneficiary lists, as officials demanded a percentage of the cash distribution (ibid.). Research in Uganda shows that women and girls were often targeted for sexual exploitation and abuse when trying to access social assistance, perpetrated by those who use their connections (or insinuated connections) to aid to exploit and abuse others (including humanitarian workers, security actors, government employees, host community members, and fellow refugees) (Potts et al. 2020a). Many displaced older people in camps in Nigeria do not receive any food assistance because they find themselves inexplicably removed from registration lists, and camp authorities have routinely failed to resolve the problems in a timely manner. Many older people described experiencing indifference, at best, from camp authorities, with older women facing particularly severe challenges (Amnesty International 2020). Ethnic and religious minorities who experience discrimination, such as the Rohingya in Myanmar, have been left out of the list of official ethnic groups in the latest census, which effectively bars them from citizenship and makes it very difficult for them to access social assistance (Radio Free Asia Myanmar Service 2014).

\section{Lack of identity cards}

People whose previous experiences of exclusion have contributed to their lack of valid identity documents find it especially difficult to access social assistance, particularly state-led assistance (UNDESA 2018). This is a big issue for stateless people but affects other groups too (ibid.). For example, transgender citizens and IDPs who have been separated from their families often lack the supporting documents needed to get an identity (ID) card (Rumbach and Knight 2014). In another example, from Pakistan, during flood relief efforts, people whose appearance did not match the gender listed on their ID documents were sometimes denied relief assistance (Paulocanning 2011). Women's lack of civic registration is a common barrier to accessing social assistance in non-crisis contexts and is likely to be exacerbated during crises. This was the case for women in Afghanistan who struggled because of their lack of ID cards (Freccero et al. 2019). Children born of wartime rape may also face difficulties accessing ID papers that would give them access to citizenship rights and social protection (Mahmood 2017).

\section{Fixed ideas about roles and capabilities}

Assumptions made about family composition can lead to some marginalised groups facing difficulties accessing the appropriate assistance if they do not fit within the standard. For example, the inaccurate assumption that older people live with and are supported by other family members - when many in fact live alone or are household heads, responsible for supporting children or dependent adults - can mean they do not receive adequate assistance to meet their household needs (Amnesty International 2020: 51; McGivern 
and Bluestone 2020: 5). In some contexts, older women are more dependent on their families for support than older men, exacerbating their poverty and lack of social status. Furthermore, they can be seen as a burden or not adequately supported. People in same-sex relationships have also struggled as a result of heteronormative understandings of family (Barbelet and Wake 2020; Edge Effect, ASC and APCOM 2018). Older people and people with disabilities are sometimes overlooked for public works programmes, which set age limits for eligibility and automatically disqualify people with disabilities. People from polygamous households may face specific challenges when it comes to naming a recipient, or distributing assistance received within one household; however, this is still an under-researched area. Family caps (limits on the number of family members who can be beneficiaries) can pose other questions, especially in contexts where social assistance programmes provide a specific number of benefits per child, for example. More research is needed in contexts of crises to understand if family caps can affect fertility behaviour and also behaviours towards needing and/or seeking social assistance.

\section{System bureaucracy}

Often, registration processes and systems are designed in an inefficient and non-people-centred way, as bureaucracy, hurdles, and the costs (financial and opportunity) are disproportionate for some groups, such as women or people with disabilities. In some cases, experiences with registration are very challenging (Freccero et al. 2019: 704). Women in Uganda and Lebanon, for example, have reported being abused in registration lines by men and exploited by aid officials, while older people in Nigeria reported repeated difficulties in getting officials to take their registration seriously (Amnesty International 2020; Potts et al. 2020b). In Afghanistan, recipients in a cash assistance programme who had been targeted because of various vulnerabilities reported that:

... officials challenged them about their migration status, bullied them, made them cry, lost their paperwork multiple times, or simply turned them away every time they came to register, coming up with various excuses about the right people not being present or being busy or in meetings.

(Freccero et al. 2019: 704)

The delays in registration significantly stalled cash disbursements and placed recipients at further risk of exploitation and abuse (ibid.).

\section{Community tensions}

Confusion about selection can also add to community tensions and leave those receiving assistance vulnerable to anger and jealously from their neighbours (ibid.: 697). It can 'exacerbate tensions between host communities and displaced communities where members of host communities were not included in cash programming despite their own situations of extreme poverty' (ibid.: 710). In socially conservative contexts, for example, unaccompanied women (such as widows and divorced women), who are already stigmatised, report an increase in tensions with others in the community upon receipt of social assistance (Blackwell et al. 2019).

\subsubsection{Distribution}

\section{Distance to distribution points}

Distribution of social assistance is a major source of risk for people from marginalised groups due to the possibilities of theft, exploitation, and abuse, and due to the accessibility challenges they often pose (Freccero et al. 2019; Handicap International 2015; Potts et al. 2020b). Distributions are often located at a distance from people's homes, which poses challenges for those with mobility issues, such as older people and some people with disabilities, who may not be able to attend and have to miss out on assistance they are entitled to (Handicap International 2015; McGivern and Bluestone 2020). The distance also poses safety challenges for people, especially women and girls, going to and from the distribution, especially if they have to travel through insecure areas, and leaves them vulnerable to theft, abuse, and exploitation related to transport to and from the site (Potts et al. 2020b). People may have to use part of their much-needed aid to pay for transport home or for the use of intermediaries to pick up their assistance for them, with the risks that entails (Freccero et al. 2019; Pearce 2015). 
The day on which assistance (cash or non-cash) is distributed can be especially risky, particularly if others in the community know of it in advance. In Cameroon, for example, there is an increased risk of attacks, home break-ins, and village raids on the dates of cash distribution, or when people receive a text message notifying them that their cash is available for pick-up, and recipients have responded by sleeping 'in the bush' to avoid being attacked or robbed when they receive or are due to receive their cash (Freccero et al. 2019: 698). Mobile money distributions do not necessarily overcome this issue if people are still using them to withdraw cash, as other people may know when the cash is collected from mobile money transfer agents, especially if they are located a distance away from where respondents live. Having to transport home bulky food or nonfood items can also increase safety risks; women and girls report experiencing sexual harassment and abuse by those they encounter trying to transport their assistance home (Potts et al. 2020a).

\section{Risks in distribution lines}

The length of time that distributions take can be an issue as for some beneficiaries it means time away from work, and, in some cases, long hours waiting in difficult weather conditions, which can be very hard for older people or people with disabilities (Freccero et al. 2019: 706). Chaotic distributions or mixed-sex lines also increase women's and girls' risk of harassment; there have also been reports of older people and people with disabilities struggling to 'fight' with young people for the assistance (Amnesty International 2020; Potts et al. 2020b; Sheppard et al. 2018). LGBTQI+ women may feel especially at risk in such lines (International Gay and Lesbian Human Rights Commission 2011).

\section{Sexual exploitation and abuse}

Sexual exploitation and abuse surrounding distribution is a major risk for women and girls across different contexts and is perpetrated by a wide variety of actors (Potts et al. 2020a; Potts et al. 2020b). In these situations, sexual and gender minorities can also find themselves vulnerable where eligibility is defined by gender. Where it is only women that are eligible, transgender people and gay men can find themselves excluded and often resort to extreme measures. In Haiti, a gay man at a camp for IDPs attempted to stand in a women-only queue dressed as a woman in order to receive food rations. He was discovered by others in the queue and harassed until he ran away, effectively barring him from accessing food in the camp (International Gay and Lesbian Human Rights Commission 2011).

\section{Risks linked to the type of assistance (modality and delivery mechanism)}

Social assistance in contexts of crises, particularly humanitarian crises, has traditionally been provided in the form of in-kind goods and services. However, as the nature of crises has shifted over recent decades, cashbased approaches have become an increasingly common strategy for the provision of assistance and are widely considered an appropriate (and sometimes preferable) substitute for in-kind assistance when conditions permit. Systematic reviews of evidence in humanitarian settings are, however, relatively rare (Doocy and Tappis 2017), but studies show that cash has different but not necessarily greater risks than inkind assistance (Szyp and Sabates-Wheeler 2019).

The mode of assistance can make a difference to the risks people face. The choice of a specific delivery mechanism could exclude certain groups among the most vulnerable - for example, children who head households may not have the right to have a bank account, women who may have less access to mobile phones, and marginalised people who may not have access to documentation necessary for phone ownership or for opening a bank account (ECHO 2013). Assistance distributed using mobile money disadvantages those who have less technological literacy, including many older people and women, and increases their reliance on intermediaries, which exposes them to greater protection risks; however, more evidence is needed about whether the use of technology does systematically exclude vulnerable groups (Freccero et al. 2019: 700; Simon 2019: 25). Mobile money agents in some contexts charge high fees, especially for shorter wait times, which may be necessary for those with urgent needs, as is often the case with many of the groups of marginalised people we focus on in this report (Freccero et al. 2019: 699). In Uganda, where cash was directly transferred to adolescent girls and boys, adolescent girls expressed more concerns than boys about the delivery mechanism. Girls requested confidentiality about their recipient status and amount and ranked mobile money as their preferred mechanism because of its low visibility (McAteer 2020; Plan International 2020). Despite these risks, cash recipients in Cameroon (for example) feel that they 
are worth managing, although a few said they preferred food as it was safer and there was less pressure to share it (Freccero et al. 2019: 701).

Food items may be bulky and hard to transport, increasing the risks of exploitation and people having to pay others to help transport them home (Amnesty International 2019; Potts et al. 2020a). Intra-household roles and relations must also be considered. For example, women often have more control over food and household goods than money. The decision about who to distribute assistance to within the household, and how, should take into account (and monitor) local social norms and dynamics, the programme objectives, and the potential impact this may have on how the assistance is used, and on household dynamics.

Conditionalities deserve a special mention, as in many crises contexts, conditionalities can be challenging, particularly if there are barriers to complying with the conditions (TRANSFORM 2020). Indeed, in settings of mass displacement, many of the requirements for receiving social assistance (such as citizenship and/or prolonged residence) can directly exclude IDPs (in case of recent forced displacement) and/or refugees (because of lack of citizenship).

\subsubsection{Post-distribution}

\section{Risks of theft}

Safety risks continue post-distribution. In certain contexts, such as Afghanistan, participation in humanitarian assistance programmes can put people at risk of extortion and retaliation by armed groups operating in their areas (Freccero et al. 2019: 705). The threat of theft and violence continues after distribution, especially if people do not have a lock box to safely store cash or other valuable items in their homes (ibid.: 700, 707). This may contribute to people quickly using up their assistance to reduce the risk of theft, but also results in them running out before the next distribution (ibid.).

\section{Undermined access to markets}

Certain barriers to access markets, which are intensified during crises, may limit the purchasing power of those in receipt of social assistance. For example, a person with disabilities may need to use a larger portion of their assistance to pay for transportation or assistance to reach the market or for specific items that may be scarce. This could also be coupled with risk of exploitation (Holden et al. 2019).

\section{Increased household tensions and violence}

Assistance may increase tensions within households, and, in some cases, lead to intimate partner violence, especially if there are disagreements over how the assistance should be used or if men feel that their role is being challenged (Freccero et al. 2019). The way that programmes are designed can contribute to this. For example, short-term programmes with unclear duration can increase tensions due to misunderstanding around why there is no more assistance, and partners may be suspected of using the assistance in other ways (e.g., on other women or to buy alcohol) when they can no longer give it to their family (ibid.).

\section{Increased community tensions}

Assistance can also increase tensions with others in the community, especially if the community does not understand the eligibility criteria or approve of the people being assisted. Single women may face additional stigma and exclusion, particularly in socially conservative contexts (Blackwell et al. 2019). In some contexts where there are community tensions around who should receive assistance, sharing cash among community members may be necessary to promote social cohesion (Freccero et al. 2019: 702). Lack of clarity around the duration of programmes can also increase tensions within communities, as people may take on financial obligations (such as rent or other outgoings) that they cannot maintain (ibid.: 702).

\section{Consequences of insufficient assistance}

If the assistance provided is not enough to cover people's basic needs, those people continue to be at risk of exploitation and abuse, pushing them to turn to negative coping mechanisms (ibid.: 706). Households with people with disabilities, for example, may have higher expenditures but lower incomes, meaning that assistance which does not account for this can keep them in poverty (UN 2021). The lack of adequate food assistance in Nigeria, for example, led older people to reduce their food consumption and turn to begging to survive (Amnesty International 2020). Women and girls may turn to survival sex to meet basic needs (Pearce 
2015). Those distributing aid can manipulate women and girls into sexual relationships in exchange for topping up their insufficient aid provisions (Potts et al. 2020b).

Table 2.1 summarises the risks of navigating access to social assistance during crises for each marginalised group, which are explained in more detail in the following sub-sections.

\section{Table 2.1: Risks of navigating access to social assistance}

\begin{tabular}{|c|c|c|c|}
\hline & \multicolumn{3}{|c|}{ Known risks of navigating access to social assistance } \\
\hline & Pre-distribution & Distribution & Post-distribution \\
\hline Women and girls & $\begin{array}{l}\text { Sexual exploitation and abuse; } \\
\text { gender-based violence; bribery; } \\
\text { lack of knowledge }\end{array}$ & $\begin{array}{l}\text { Sexual exploitation and abuse; } \\
\text { gender-based violence; using part } \\
\text { of assistance for transport home; } \\
\text { use of male intermediaries; theft }\end{array}$ & $\begin{array}{l}\text { Household tensions; intimate } \\
\text { partner violence; insufficient } \\
\text { assistance; sexual exploitation } \\
\text { and abuse; community tensions }\end{array}$ \\
\hline $\begin{array}{l}\text { Children and } \\
\text { adolescents }\end{array}$ & $\begin{array}{l}\text { Physical, emotional, or sexual } \\
\text { abuse; marginalisation; online } \\
\text { threats; undermined work and } \\
\text { income }\end{array}$ & $\begin{array}{l}\text { Harmful work; stigma; } \\
\text { exploitation; theft; violence; } \\
\text { physical and sexual abuse; } \\
\text { undermined childcare }\end{array}$ & $\begin{array}{l}\text { Violence; sexual exploitation } \\
\text { and abuse; tensions; stigma; } \\
\text { health and nutrition; harmful } \\
\text { work; diversion of assistance }\end{array}$ \\
\hline Youth & $\begin{array}{l}\text { Bias; marginalisation; bribery; } \\
\text { violence; neglect }\end{array}$ & Insecurity; violence & $\begin{array}{l}\text { Violence; stigma; labour } \\
\text { competition; debt }\end{array}$ \\
\hline Older people & $\begin{array}{l}\text { Neglect; marginalisation; } \\
\text { exclusion; lack of knowledge of } \\
\text { providers; lack of participation in } \\
\text { programme design }\end{array}$ & $\begin{array}{l}\text { Access issues; missing out on } \\
\text { distributions; use of } \\
\text { intermediaries; theft; struggles } \\
\text { with technology }\end{array}$ & Theft; insufficient assistance \\
\hline $\begin{array}{l}\text { People with } \\
\text { disabilities }\end{array}$ & $\begin{array}{l}\text { Neglect; discrimination; lack of } \\
\text { access; lack of knowledge of } \\
\text { providers; lack of accessible } \\
\text { information; lack of participation } \\
\text { in programme design }\end{array}$ & $\begin{array}{l}\text { Access issues; missing out on } \\
\text { distributions; attitudinal barriers; } \\
\text { use of intermediaries; theft; } \\
\text { sexual exploitation and abuse; } \\
\text { gender-based violence }\end{array}$ & $\begin{array}{l}\text { Theft; assistance quickly used } \\
\text { up; insufficient assistance; } \\
\text { community tensions; abuse }\end{array}$ \\
\hline $\begin{array}{l}\text { Ethnic and } \\
\text { religious minorities }\end{array}$ & $\begin{array}{l}\text { Marginalisation; discrimination; } \\
\text { neglect; elite capture }\end{array}$ & $\begin{array}{l}\text { Violence; discrimination; } \\
\text { marginalisation; neglect; informal } \\
\text { work }\end{array}$ & $\begin{array}{l}\text { Social injustice; 'impartiality' } \\
\text { undermining monitoring }\end{array}$ \\
\hline $\begin{array}{l}\text { Sexual and } \\
\text { gender minorities }\end{array}$ & $\begin{array}{l}\text { Marginalisation; neglect; } \\
\text { invisibility }\end{array}$ & $\begin{array}{l}\text { Discrimination; violence; } \\
\text { marginalisation; stigma }\end{array}$ & $\begin{array}{l}\text { Stigma; violence; psychological } \\
\text { damage }\end{array}$ \\
\hline
\end{tabular}

\subsubsection{Outcomes of not receiving social assistance for marginalised people}

\section{Deprivation, household tensions, and negative coping mechanisms}

Women and girls, children and youth, older people, people with disabilities, religious and ethnic minorities, and sexual and gender minorities are among those most negatively affected by the impacts of crises, due to a number of factors, including the exclusion they experience before and during the crisis. Many find themselves in desperate situations and suffer from deprivation, poverty, and food insecurity, often with fewer means of coping. These difficulties can cause tensions within households, which, in some cases, result in intimate partner violence (Cross et al. 2018). As a result, very often marginalised people who do not receive social assistance remain stuck in these desperate situations and vulnerable to exploitation and abuse. They may turn to negative coping mechanisms such as harmful child labour, child marriage, survival sex, begging, reduced food consumption, or substance abuse (Amar, Hames and Clifton 2019; Amnesty International 2020; Lehrer 2009; McGivern and Bluestone 2020; Pearce 2015). The disempowering nature of crises and the harmful impact of shocks and violence often have consequences for people's dignity and can result in high levels of mental distress, which are not commonly recognised in the literature (Blackwell et al. 2019; Sheppard et al. 2018). 
However, there may be some benefits to not accessing social assistance in some circumstances, for some people. If social assistance is targeted at marginalised people in contexts where they are severely stigmatised - for example, people with disabilities or LGBTQI+ people - remaining invisible and not identifying themselves can be a means of staying safe (UNDESA 2018). Staying out of social assistance programmes, especially temporary ones, may also help keep intact the social support systems people use to cope (Blackwell et al. 2019). Women in Syria, for example, noted that the support they had been receiving from family and neighbours had stopped when people found out they were receiving cash assistance, and they worried that the community tensions that resulted from the programme meant that these networks were lost (ibid.).

Research about urban refugees has revealed how invisibility can be a deliberate strategy for LGBTQI+ people. A Burmese LGBTQI+ refugee from the Mae La camp in Thailand highlighted how he grappled with having the confidence to meet with other LGBTQI+ individuals as they all feared identification as LGBTQI+. He notes, 'We were asked by UNHCR to consider establishing a more formal community-based organisation but resisted as we did not believe we could offer our members sufficient protection if we were to become more visible...' (Moses 2013). There is evidence that staying 'under the radar' is an approach adopted by some religious and ethnic minorities. Due to risk of physical violence linked to sectarian tensions and fears of reprisal attacks in Syria, Syrian Christian and Druze refugees often choose not to register with UNHCR (and, in so doing, exclude themselves from any social assistance they would be entitled to) in order to avoid formal refugee camps; instead, they seek housing in urban centres where they face isolation, stigmatisation, and (perceived or real) discrimination in accessing humanitarian aid and assistance (Avis 2019).

\section{Sexual exploitation and abuse}

In contexts where social assistance is rife with sexual exploitation and abuse, those who can survive through other means will be less exposed to these risks. However, such exploitation also exists outside of formal social assistance structures and because many people in marginalised groups need social assistance to survive, they navigate these risks both outside of and within the formal social assistance system (Potts et al. 2020 b). For example, host communities can engage in sexual exploitation and abuse of displaced women and girls trying to access food or shelter items from the community around them (ibid.).

\subsubsection{Outcomes of receiving social assistance for marginalised people}

\section{Improved food security and nutrition}

While not specifically focused on marginalised people, research looking at cash assistance in various humanitarian settings has found that it can improve food security and help households meet their basic needs (Blackwell et al. 2019: 254). Cash transfers - both in Uganda to older people (Dietrich et al. 2017; Merttens et al. 2016; UNDESA 2018) and in Yemen to adults (Ecker, Maystadt and Guo 2019) - improved children's nutrition.

\section{Improved health, education, and wellbeing}

If the programme is well designed, it can also improve health and wellbeing among people affected by crises (Blackwell et al. 2019: 254). Programmes have allowed families to pay for school fees (Freccero et al. 2019). While social assistance programmes are ongoing, they have been found to relieve the stress that people and households are under during crises, as people are able to provide for themselves and their families (Blackwell et al. 2019; Cross et al. 2018; Simon 2019). For example, research on public works programming in Rwanda shows that an inclusive programme design (i.e., with childcare services at the work site or the establishment of wider community-based childcare mechanisms) can improve children's wellbeing (Roelen and Shelmerdine 2014). For women in Syria, having money of their own gives them a sense of power and dignity (Blackwell et al. 2019).

\section{Reduced economic vulnerability}

More ambitious objectives, such as livelihood promotion, have increasingly been linked to social assistance programming. A key reason for this is the assumption of an employment-peace nexus in fragile and conflictaffected settings (FCAS). This is the case of many 'cash-plus' programmes. For example, evidence from Jovenes en Accion (Youth in Action) in Colombia finds that it reduces informal employment and improves 
labour market outcomes among youth (Attanasio et al. 2017). And research in Uganda on the Youth Opportunities programme highlights that after four years, it resulted in increased hours of work and earnings (Blattman, Fiala and Martinez 2014).

\section{Reduction in negative coping mechanisms}

The limited evidence in humanitarian settings also suggests that 'cash programmes have the potential to reduce a household's reliance on negative coping, including taking children out of school, reducing food consumption, depleting savings, or selling assets' (Blackwell et al. 2019: 255). There is mixed anecdotal evidence about whether cash-based interventions in humanitarian contexts reduce sex work as a negative coping strategy (Simon 2019). There is also research that looks at the trade-offs between cash and the child work-education balance. For example, Pakistan's Female School Stipend Programme reduced girls' labour force participation from 9 per cent to 5 per cent (Alam, Baez and Del Carpio 2011; Presler-Marshall and Jones 2018).

\section{Improvement in community relations}

Social assistance can also result in reduced tensions among community members, such as Plan International's cash and voucher assistance (CVA) programme in Uganda, through which beneficiaries cooperated with non-beneficiaries (McAteer 2020; Plan International 2020). Enabling people to pay their debts and reciprocate favours can also have a positive effect on community relations (Blackwell et al. 2019: 267; Cross et al. 2018; Freccero et al. 2019). Furthermore, there is more and more research looking at any links between social assistance and peacebuilding (or social cohesion), such as the Sustainable Transformation of Youth in Liberia, which was accompanied by large, sustained falls in crime and violence (Blattman, Jamison and Sheridan 2017).

\section{Improved protection outcomes}

Limited evidence suggests that well-designed cash-based social assistance can reduce household tensions and gender-based violence, including intimate partner violence, as well as potentially protecting against sexual exploitation and abuse (Cross et al. 2018; Simon 2019). However, there are concerns that the positive impact on intimate partner violence as a result of a reduction in income-related tension, frustration, and fighting may only be temporary (Cross et al. 2018). Cash transfers to girls in Somalia resulted in a reduction of work outside the home, reducing their commuting and thus related threats of violence (Women's Refugee Commission and Adeso 2018).

\section{Exposure to violence}

Even though the evidence of outcomes in crises contexts is still limited, research shows some increased risks of social assistance in some circumstances, including physical and mental harm (Stark and Ager 2011; Vu et al. 2014). Programme evaluations in humanitarian contexts have found that 'cash assistance can expose beneficiaries to violence and other unintended risks' (Blackwell et al. 2019: 255). These include 'increased household and community tension, increased family violence, and/or exposure to theft and stigma, as well as other documented risks', such as sexual exploitation and abuse, especially if there has been a disregard for gender and resource-control dynamics (Blackwell et al. 2019: 255; Freccero et al. 2019; Cross et al. 2018). Food and other bulky assistance can increase people's exposure to exploitation and abuse as people can struggle to get the assistance home safely (Amnesty International 2019; Potts et al. 2020a; Potts et al. $2020 b)$. 'Socially protecting' assistance has also been linked with exclusion, harassment, and gender-based and sexual violence in shelters for LGBTQI+ persons and families, such as in the aftermath of the 2010 Haitian earthquake, for example (International Gay and Lesbian Human Rights Commission 2011).

\section{Stigma, shame, and increased mental health problems}

Strict social norms in contexts of natural disasters and forced displacement can result in LGBTQI+ people experiencing humiliation. For some bakla (people who were assigned a male gender at birth but have feminine identity and appearance) in the Philippines, social norms associated with their masculine bodies compel them to use male bathrooms in temporary shelters, where they suffer from mockery and harassment (Rumbach and Knight 2014). 
Survivors of sexual exploitation and abuse may experience shame and depression and face negative reactions such as stigma, blaming or shaming while accessing social assistance (Potts et al. 2020a; Potts et al. 2020b).

Receiving social assistance can also be a disempowering experience, and the harmful impact of being dependent on aid often has consequences for people's dignity and mental health that are not commonly recognised in the literature.

\section{Community tensions}

Evidence from studies of cash transfer programmes in emergency settings has found that community tensions can be exacerbated by poor programme design and implementation, especially as a result of failure to communicate targeting and eligibility requirements (Simon 2019: 19). Context also matters for community expectations about whether aid should be shared with others in the community or not. There is some suggestion from Cameroon, for example, that there is a greater expectation from others in the community that cash assistance will be shared, whereas food assistance does not have the same expectations; yet in other contexts the reverse is the case (Freccero et al. 2019: 701).

\section{Disrupted social support systems and inadequate assistance}

Short-term social assistance programmes in crises can also disrupt the social support systems people use to cope, as people who used to give them assistance may feel resentful or no longer see the need to provide support (Blackwell et al. 2019). If such programmes are temporary, they risk leaving people with neither formal nor informal social assistance. Inadequate levels of social assistance, whether cash or food or other forms, can also leave people hungry and distressed, and vulnerable to exploitation and negative coping mechanisms (Amnesty International 2020; McGivern and Bluestone 2020; Sheppard et al. 2018). Food assistance may not be appropriate for the specific nutritional needs of older people, people with disabilities, and children, which means it may not be as effective as it could be (Barbelet 2018; Sheppard et al. 2018).

Table 2.2 summarises the outcomes of receiving or not receiving social assistance during crises for each marginalised group, drawing from the sub-sections that follow. 
Table 2.2: Potential outcomes of receiving or not receiving social assistance

\begin{tabular}{|c|c|c|c|c|}
\hline & \multicolumn{2}{|c|}{ Outcomes of not receiving social assistance } & \multicolumn{2}{|c|}{ Outcomes of receiving social assistance } \\
\hline & Positive & Negative & Positive & Negative \\
\hline $\begin{array}{l}\text { Women and } \\
\text { girls }\end{array}$ & $\begin{array}{l}\text { Social support } \\
\text { networks } \\
\text { maintained }\end{array}$ & $\begin{array}{l}\text { Vulnerable to sexual } \\
\text { exploitation and abuse and } \\
\text { gender-based violence; } \\
\text { increased family tensions; } \\
\text { increased intimate partner } \\
\text { violence; deprivation }\end{array}$ & $\begin{array}{l}\text { Reduced economic } \\
\text { vulnerability - therefore } \\
\text { reducing vulnerability to } \\
\text { exploitation and abuse; } \\
\text { reduced household } \\
\text { tensions; reduced intimate } \\
\text { partner violence; reduced } \\
\text { early and forced marriage; } \\
\text { reduced transactional sex; } \\
\text { improved mental health and } \\
\text { wellbeing; improved } \\
\text { household decision-making; } \\
\text { improvements in health, } \\
\text { nutrition, and housing; } \\
\text { improved relationships with } \\
\text { neighbours }\end{array}$ & $\begin{array}{l}\text { Unhappy men; increased } \\
\text { household tensions; } \\
\text { increased intimate partner } \\
\text { violence; reinforced } \\
\text { gender stereotypes; } \\
\text { worries for the future; } \\
\text { disruption to social } \\
\text { networks providing } \\
\text { assistance; increased } \\
\text { stigma, gossip, and } \\
\text { exclusion; social tensions; } \\
\text { increased burden on } \\
\text { women; shame and } \\
\text { depression resulting from } \\
\text { experiences of sexual } \\
\text { exploitation and abuse }\end{array}$ \\
\hline $\begin{array}{l}\text { Children and } \\
\text { adolescents }\end{array}$ & & $\begin{array}{l}\text { Harmful work; child marriage; } \\
\text { undermined nutrition, health, } \\
\text { and education; physical, } \\
\text { sexual and/or emotional } \\
\text { violence; poverty }\end{array}$ & $\begin{array}{l}\text { Accessibility to education, } \\
\text { nutrition, and health } \\
\text { services; reduced violence; } \\
\text { food security; livelihoods } \\
\text { resilience; reduced negative } \\
\text { coping mechanisms } \\
\text { (harmful work); social } \\
\text { cohesion }\end{array}$ & $\begin{array}{l}\text { Harmful work; emotional, } \\
\text { physical, and sexual } \\
\text { violence and exploitation; } \\
\text { stigma; undermined } \\
\text { health or education; } \\
\text { social tensions }\end{array}$ \\
\hline Youth & & $\begin{array}{l}\text { Discrimination; violence; social } \\
\text { tension; alcoholism; } \\
\text { humiliation }\end{array}$ & $\begin{array}{l}\text { Labour market outcomes; } \\
\text { reduced tensions and } \\
\text { violence; enhanced } \\
\text { education; improved soft } \\
\text { skills }\end{array}$ & $\begin{array}{l}\text { Stigma; vulnerability; } \\
\text { violence; sexual } \\
\text { exploitation; migration }\end{array}$ \\
\hline Older people & & $\begin{array}{l}\text { Food insecurity; being forced } \\
\text { to beg; substandard } \\
\text { accommodation; deprivation }\end{array}$ & Improved food security & $\begin{array}{l}\text { Frustration; feeling like a } \\
\text { burden; inadequate } \\
\text { assistance forcing people } \\
\text { to beg }\end{array}$ \\
\hline $\begin{array}{l}\text { People with } \\
\text { disabilities }\end{array}$ & & $\begin{array}{l}\text { Deprivation; poverty; reduced } \\
\text { health and education; begging; } \\
\text { food insecurity; sexual } \\
\text { exploitation and abuse }\end{array}$ & $\begin{array}{l}\text { Improved health and } \\
\text { education }\end{array}$ & $\begin{array}{l}\text { Inadequate assistance } \\
\text { leading to hunger and } \\
\text { distress }\end{array}$ \\
\hline $\begin{array}{l}\text { Ethnic and } \\
\text { religious } \\
\text { minorities }\end{array}$ & $\begin{array}{l}\text { Reduced risk of } \\
\text { physical violence; } \\
\text { marginalisation }\end{array}$ & $\begin{array}{l}\text { Undermined health, nutrition, } \\
\text { education, and livelihoods; } \\
\text { marginalisation; isolation; } \\
\text { stigma; social tension; social } \\
\text { inequalities }\end{array}$ & $\begin{array}{l}\text { Livelihood resilience; } \\
\text { specific needs met; } \\
\text { invisibility }\end{array}$ & $\begin{array}{l}\text { Persecution; violence; } \\
\text { repatriation; repercussion; } \\
\text { exclusion; social tension }\end{array}$ \\
\hline $\begin{array}{l}\text { Sexual and } \\
\text { gender } \\
\text { minorities }\end{array}$ & $\begin{array}{l}\text { Invisibility and } \\
\text { autonomy; } \\
\text { physical safety }\end{array}$ & $\begin{array}{l}\text { Undermined protection, } \\
\text { livelihoods, health care, and } \\
\text { other basic needs; stigma; } \\
\text { violence; psychological } \\
\text { distress; isolation; violence }\end{array}$ & $\begin{array}{l}\text { Enhanced access to safe } \\
\text { services }\end{array}$ & $\begin{array}{l}\text { Stigma; physical and } \\
\text { sexual violence; coping } \\
\text { mechanisms (changing } \\
\text { behaviour); forced } \\
\text { displacement }\end{array}$ \\
\hline
\end{tabular}




\section{Women and girls}

Most of the social assistance in crises literature relating to gender focuses on women and girls rather than men and boys, hence the predominant focus in this section on the experiences of women and girls. Table 3.1 highlights and introduces the main findings for this marginalised group in terms of risks (pre-distribution, during, and post-distribution) and outcomes (positive and negative of receiving or not receiving social assistance) of navigating access to social assistance.

\section{Table 3.1: Summary of findings relating to women and girls}

\begin{tabular}{|c|c|c|}
\hline & & Women and girls \\
\hline \multirow{3}{*}{$\begin{array}{l}\text { Known risks } \\
\text { of navigating } \\
\text { access to } \\
\text { social } \\
\text { assistance }\end{array}$} & Pre-distribution & Sexual exploitation and abuse; gender-based violence; bribery; lack of knowledge \\
\hline & Distribution & $\begin{array}{l}\text { Sexual exploitation and abuse; gender-based violence; using part of assistance for } \\
\text { transport home; use of male intermediaries; theft }\end{array}$ \\
\hline & Post-distribution & $\begin{array}{l}\text { Household tensions; intimate partner violence; insufficient assistance; sexual } \\
\text { exploitation and abuse; community tensions }\end{array}$ \\
\hline \multirow{2}{*}{$\begin{array}{l}\text { Outcomes of } \\
\text { not receiving } \\
\text { social } \\
\text { assistance }\end{array}$} & Positive & Social support networks maintained \\
\hline & Negative & $\begin{array}{l}\text { Vulnerable to sexual exploitation and abuse and gender-based violence; increased } \\
\text { family tensions; increased intimate partner violence; deprivation }\end{array}$ \\
\hline \multirow[t]{2}{*}{$\begin{array}{l}\text { Outcomes of } \\
\text { receiving } \\
\text { social } \\
\text { assistance }\end{array}$} & Positive & $\begin{array}{l}\text { Reduced economic vulnerability - therefore reducing vulnerability to exploitation } \\
\text { and abuse; reduced household tensions; reduced intimate partner violence; } \\
\text { reduced early and forced marriage; reduced transactional sex; improved mental } \\
\text { health and wellbeing; improved household decision-making; improvements in } \\
\text { health, nutrition, and housing; improved relationships with neighbours }\end{array}$ \\
\hline & Negative & $\begin{array}{l}\text { Increased household tensions; increased intimate partner violence; reinforced } \\
\text { gender stereotypes; worries for the future; disruption to social networks providing } \\
\text { assistance; increased stigma, gossip, and exclusion; social tensions; increased } \\
\text { burden on women; shame and depression resulting from experiences of sexual } \\
\text { exploitation and abuse }\end{array}$ \\
\hline
\end{tabular}

\subsection{Needs}

Pre-existing gender inequalities mean that women and girls are often more exposed to greater loss of livelihoods, security, and lives, both during and in the aftermath of a crisis (Simon 2018: 2). Crisis conditions cause stress and anxiety, especially in relation to how they can meet their family's basic needs ${ }^{6}$ (Blackwell et al. 2019: 261). Economic insecurity also leaves women and girls more at risk of exploitation, and their families may encourage or force them into such relationships because they need the assistance (Blackwell et al. 2019: 260; Potts et al. 2020a: 13). Gender-based violence such as intimate partner violence, early and forced marriage, and sex work are exacerbated in crises conditions, which increases tensions and dependency, and can present further risks to safety (Blackwell et al. 2019: 259; Cross et al. 2018: 3).

Women and girls, especially those living on their own without a male provider, spouse, or familial support, or with precarious legal status, are among those more affected by sexual exploitation and abuse in crises (Blackwell et al. 2019: 259; Human Rights Watch (HRW) 2019; Potts et al. 2020a: 2, 17; Potts et al. 2020b: 3 , 26; Simon 2018: 2). Shame, stigma, and the desperate need for assistance to survive, combined with powerlessness, vulnerability, and lack of awareness among those affected create an enabling environment for exploitation and abuse (Potts et al. 2020a: 3; Potts et al. 2020b: 3, 14, 17).

\footnotetext{
${ }^{6}$ Men also suffer stress and anxiety over meeting their family's basic needs.
} 
Gender norms and overlapping social and power dynamics also influence women's and girls' access to and control of assistance, and thus their ability to benefit from social assistance programmes (Blackwell et al. 2019: 260).

\subsection{Risks}

\subsubsection{Pre-distribution}

Pre-distribution poses a number of risks for women and girls. Information about aid (or lack of the same) can be used to exploit and abuse women and girls. For example, research in Lebanon and Uganda finds that aid workers or others made women and girls believe they would not gain access to aid unless they entered into sexually exploitative relationships, or that aid workers took advantage of the information they held about women's and girls' vulnerability status to exploit them (Potts et al. 2020a: 9; Potts et al. 2020b: 10).

Spouses and male relatives may also withhold information regarding aid registration to control women's and girls' movement and access to aid, itself a form of gender-based violence (Potts et al. 2020a: 27).

Registration is a point in the social assistance programme cycle with significant potential for sexual exploitation and abuse for a variety of reasons. A lack of clarity over who has the power to decide if someone is registered or not, or how much assistance they are entitled to, opens the space for sexual and financial exploitation based on false promises and raised expectations (Freccero et al. 2019: 697; HRW 2019; Potts et al. 2020b: 10). Aid workers may offer to register women and girls more quickly in exchange for sex, when women may urgently need the aid due to the desperate situations, they find themselves in (Potts et al. 2020a: 10).

If registration events are chaotic and disorganised, it presents opportunities for gender-based violence, including sexual harassment and assault of women by men standing in the same lines as them (Potts et al. 2020b: 26-27). The way in which social assistance programmes are designed may not take into consideration the needs of women; for example, cash-for-work programmes often do not account for the needs of pregnant or lactating women or provide childcare (Cross et al. 2018: 15).

Indeed, many of the pre-distribution risks are threats related to sexual exploitation and abuse but there are further considerations. For example, barriers around the costs associated with registration processes or travel to get to registration, including childcare and transport (Simon 2018); also, eligibility criteria may include or exclude vulnerable women such as single mothers, women without the necessary ID, etc. (Rauf 2016).

\subsubsection{Distribution}

Distribution is one of the most significant points in the programme cycle for sexual exploitation and abuse of women and girls (Potts et al. 2020b: 11). This occurs both during interactions at distribution points or when people are moving to or from distributions (Potts et al. 2020a: 8; Potts et al. 2020b: 2). In Lebanon, for example, women were offered cash assistance in exchange for sexual relationships and/or threatened with other types of violence if they refused; while in Uganda, workers offered to help by distributing food more quickly (serving women or girls first or taking them to the front of the line), promised more food, or granted access to the point of distribution (i.e. by security guards), contingent on sex (Potts et al. 2020a: 27; Potts et al. 2020b: 7, 11).

Disorganisation, overcrowding, and mixed-sex waiting lines at distribution points create space for sexual harassment and targeting of women and girls by refugee boys and men who are there to benefit from the distribution (Potts et al. 2020a: 8, 26; Potts et al. 2020b: 15, 23, 25).

Risks of abuse by aid workers, taxi drivers, and the men and boys in the community increased if aid was distributed in areas that women were unfamiliar with, or if the assistance they were provided with was hard to transport home (Potts et al. 2020a: 8, 10, 16; Potts et al. 2020b: 3, 11, 23). Items that are hard to transport lead to women and girls having to sell part of the aid they needed to get home, which could cause problems with their partners if they returned home with less assistance than was expected (Potts et al. 2020b: 8, 23). Some male partners reacted with suspicion or violence if distributions take a long time (Potts et al. 2020b: 15). 
The dangers posed by travelling for distributions mean that women may send male intermediaries in their place, which increases the risks of delays in receiving assistance, as well as theft (Freccero et al. 2019: 699). Other dangers, such as thefts on the way home from distribution centres, are also of concern to women (Freccero et al. 2019: 704).

Adolescent girls (especially those without parents) and single, divorced, or widowed women are especially at risk of sexual exploitation and abuse, as are female-headed households or those who were economically vulnerable or without a strong support network (Potts et al. 2020a: 3, 9; Potts et al. 2020b: 12).

\subsubsection{Post-distribution}

Women and girls also faced a number of issues after taking their assistance home. Social assistance can result in increased household tensions and intimate partner violence due to disputes over matters such as how the assistance is used (Freccero et al. 2019: 707; Potts et al. 2020a: 27; Potts et al. 2020b: 23). Some women have to hide their cash from their partners to prevent them from wasting it (Freccero et al. 2019: 700701). Men in Cameroon, for example, also noted the increases in tension, especially if there was lack of clarity over the duration of the assistance because when they stopped receiving it, they were suspected of using it on themselves or other women (Freccero et al. 2019: 702).

Receipt of social assistance can also cause tensions within the wider community, especially if the inclusion criteria are unclear; or for women living on their own in countries where they are stigmatised, such as in Syria, for example (Blackwell et al. 2019: 264).

Women and girls continue to struggle if the assistance provided is insufficient to meet basic needs, forcing them into exploitative situations to survive and provide for their families (Freccero et al. 2019: 702; Potts et al. 2020b: 8-9).

\subsection{Outcomes}

Not receiving social assistance during a crisis can leave women and girls trapped in desperate situations, stressed and unable to meet basic needs, living in poverty and deprivation, more vulnerable to intimate partner violence due to tensions in the home, and at risk of sexual exploitation and abuse as they try to find ways to provide for their needs and those of their families (Blackwell et al. 2019). Levels of intimate partner violence increase when there are not enough resources to meet basic needs, when there is unemployment, and when heads of households feel powerless to provide for their families (Cross et al. 2018: 17). Negative coping strategies include survival sex, while in some cases, families may be desperate to alleviate their family's situation and so turn to early marriage as a coping strategy to secure their daughters' future (Blackwell et al. 2019; Cross et al. 2018: 19).

However, evidence from humanitarian crises contexts about the outcomes of receiving social assistance for women and girls is much more limited and mixed, compared to the evidence from development contexts (Blackwell et al. 2019: 254; Cross et al. 2018: 3; Simon 2018: 1; Simon 2019: 1).

There are mixed results on the impact of cash on gender-based violence in humanitarian contexts, although the limited evidence available suggests that it is largely positive (Blackwell et al. 2019: 255; Simon 2019: 1; Cross et al. 2018: 5). ${ }^{7}$ A review of evidence on the effects of cash-based interventions noted a few key findings from the small amount of evidence from humanitarian contexts: (1) cash transfers are consistently found to have the potential to reduce household tensions, as the extra income relieves the ongoing stress associated with provision for the family (with the exception of polygamous households in some contexts); (2) a few studies suggest that the coping behaviours of women can obscure the relationship between cash transfers and the reported incidence of abuse - for example, defusing the potential for violence by quickly spending the transfer, giving their partners a portion of the income or reporting incidents of violence to programme staff; and (3) a few studies raise concerns that purposeful targeting of women can lead to the marginalisation or emasculation of men, increasing the risk of negative outcomes (Simon 2019: 1, 11; see also Cross et al. 2018: 10). Small transfers were seen to be a help for women in performing their regular tasks, so less of a threat to the traditional male role than a more substantial transfer aimed at them (Simon

\footnotetext{
7 'In the development context, cash transfers have been largely associated with a reduction in reported physical violence against women by male partners, although the effects on emotional abuse and spousal controlling behaviour, however, are more mixed' (Cross et al. 2018: 4).
} 
2019: 17). Relieving income-related household tensions had a positive impact on levels of intimate partner violence, although there are concerns that this only lasts for the duration of assistance being provided (Cross et al. 2018: 17).

As one study concludes, 'The evidence to date on how cash transfers in humanitarian settings influence the protection of women is limited, largely anecdotal and mixed' (Simon 2019: 17). There is a small amount of emerging evidence that cash-based interventions in humanitarian settings have a positive protection impact on sexual exploitation and abuse of women (Cross et al. 2018: 18; Freccero et al. 2019: 688). The effects of cash transfers in humanitarian settings on negative coping mechanisms such as engaging in survival sex are largely unresearched and not well understood (Cross et al. 2018: 10, 20; Simon 2019: 13). There is mixed anecdotal evidence about whether cash-based interventions in humanitarian contexts reduce sex work (Simon 2019: 2, 13). Some evidence from Syrian refugees in Jordan and Somalia suggests that cash transfers helped delay other negative coping strategies such as early marriage (Cross et al. 2018: 19).

There is a relatively large amount of evidence that cash can strengthen women's role in household decisionmaking and make them feel more independent, self-reliant, and able to express their needs. However, in many fragile contexts, men are still believed to be the primary decision makers, and short-term programmes mean that patriarchal household dynamics remain unchanged (Blackwell et al. 2019: 264; Cross et al. 2018: 11, 16; Simon 2019: 2, 16).

Assistance helped families improve their health, nutrition, housing, education, dignity, self-worth, and social status, for women and men alike (Freccero et al. 2019: 696; Simon 2019: 2, 18). A study of a cash transfer programme in Somalia found that the 'greatest gains in feelings of well-being (as reflected through social status) were those with greater vulnerabilities such as widowed or divorced beneficiaries, older recipients and women' (Simon 2019: 18). Even short periods of assistance were able to help alleviate women's stress and anxiety over how to provide for their family's needs, as well as relieving their sense of shame at being dependent on others or a burden, although short-term assistance programmes created anxiety and stress over what would happen when the assistance ended (Blackwell et al. 2019: 261).

Relationships with the wider community improved when people could repay loans and no longer had to rely on others for gifts and favours, but instead could sometimes share their disbursements (Blackwell et al. 2019: 262-3; Cross et al. 2018: 21; Freccero et al. 2019: 696).

On the other hand, social assistance programmes can sometimes 'increase rates of intimate partner violence, gender-based and intergenerational violence, worsen stigma towards beneficiaries, and aggravate social tension in communities', especially 'when women are selected as beneficiaries without regard for gender and resource-control dynamics' (Cross et al. 2018: 15, 18; Freccero et al. 2019: 688).

Social assistance programmes may disrupt existing social support systems and create social tensions that persist beyond the end of the programme (Blackwell et al. 2019: 266). In Syria, for example, women worried that bad feelings generated by them receiving assistance while others did not, would mean that the support they were receiving from their social networks prior to the cash programme would stop permanently, especially as it had often stopped when people found out they were receiving cash (Blackwell et al. 2019: 264).

Social assistance programming can also expose women and girls to sexual exploitation and abuse, which can result in survivors experiencing shame, depression, and fear around reporting the abuse (Potts et al. 2020a: 13, 30; Potts et al. 2020b: 27). If they disclose it or any other gender-based violence they have experienced to their family and communities, they may be met with negative reactions such as stigma, blaming or shaming, gossip about them, limits on their freedom of movement, disbelief, and, in some cases, being forced to marry the perpetrator or have further violence perpetrated against them (Potts et al. 2020a: 13, 29; Potts et al. 2020b: 13, 27). 


\section{Children and adolescents}

\subsection{Children, adolescents and youth: classification challenges}

Researchers struggle to define the span of time before adulthood. The focus on research that concerns nonadults merits some thought: which age groups are considered children, which are considered adolescents, and which are considered youth? Do they overlap? Do they vary? Until recently, childhood was typically portrayed as a period of dependence, particularly during school age and often up until 17 years of age. On the other hand, adulthood has been traditionally characterised by financial and socioemotional independence from the family of origin. Leaving school, along with starting work, developing an independent social network and identity, and forming a family through marriage and parenthood have been key markers of this transition.

'Youth' is often understood as a period of transition from the dependence of childhood to the independence of adulthood. Age is also used to define 'youth', particularly in relation to education and employment. Depending on the context and organisation, 'youth' may be defined as people aged 15-24 or 15-35, aiming to cover people from the age when they may leave compulsory education, until the age they start work. 'Adolescence' can be understood as the period of a person's life between puberty and maturity (adulthood) generally covering the teenage years, but not always, and in different societies it is associated with certain privileges and responsibilities. Definitions often include the upper age range from childhood (15-17 years), or wider categorisations may also cover early youth (such as those aged 10-19 years). In many societies and communities, these categories tend to be more fluid than these fixed age groups, as the time spent (as well as start and end date) in education and employment is not homogeneous, as well as any responsibilities adjudicated to them. The challenges people face, particularly but not exclusively in contexts of protracted crisis, cause disruptions in their life trajectories and therefore often result in a shorter childhood and early start of youth, for example. This is why definitions often vary, usually following a specific age range depending on the context. For the purpose of this paper, we use the terms as applied in the literature.

Table 4.1 highlights and introduces the main findings for this marginalised group in terms of risks (predistribution, during, and post-distribution) and outcomes (positive and negative of receiving or not receiving social assistance) of navigating access to social assistance.

\section{Table 4.1: Summary of findings relating to children and adolescents}

\begin{tabular}{|c|c|c|}
\hline & & Children and adolescents \\
\hline \multirow{3}{*}{$\begin{array}{l}\text { Known risks of } \\
\text { navigating access to } \\
\text { social assistance }\end{array}$} & Pre-distribution & $\begin{array}{l}\text { Physical, emotional, or sexual abuse; marginalisation; online threats; } \\
\text { undermined work and income }\end{array}$ \\
\hline & Distribution & $\begin{array}{l}\text { Harmful work; stigma; exploitation; theft; violence; physical and sexual } \\
\text { abuse; undermined childcare }\end{array}$ \\
\hline & Post-distribution & $\begin{array}{l}\text { Violence; sexual exploitation and abuse; tensions; stigma; health and } \\
\text { nutrition; harmful work; diversion of assistance }\end{array}$ \\
\hline \multirow{2}{*}{$\begin{array}{l}\text { Outcomes of not } \\
\text { receiving social } \\
\text { assistance }\end{array}$} & Positive & No positive effects identified \\
\hline & Negative & $\begin{array}{l}\text { Harmful work; child marriage; undermined nutrition, health, and } \\
\text { education; physical, sexual and/or emotional violence; poverty }\end{array}$ \\
\hline \multirow[t]{2}{*}{$\begin{array}{l}\text { Outcomes of receiving } \\
\text { social assistance }\end{array}$} & Positive & $\begin{array}{l}\text { Accessibility to education, nutrition, and health services; reduced } \\
\text { violence; food security; livelihoods resilience; reduced negative coping } \\
\text { mechanisms (harmful work); social cohesion }\end{array}$ \\
\hline & Negative & $\begin{array}{l}\text { Harmful work; emotional, physical, and sexual violence and } \\
\text { exploitation; stigma; undermined health or education; social tensions }\end{array}$ \\
\hline
\end{tabular}




\subsection{Needs}

Despite the recent increased focus on gender- and disability-sensitive social assistance, this has not often sought to address child protection vulnerabilities with an intersectional lens. This is a surprising gap given the heightened risks of abuse and exploitation facing specific groups of children and adolescents during crises (e.g., displacement, loss of caregivers and resources, increased distress) due to unequal power dynamics. This is the case for children with intellectual disabilities, who have limited access to education as public schools in FCAS are often not accessible and do not provide a welcoming environment for students with special needs (UNHCR and World Food Programme (WFP) 2017). The requirements for accessing social assistance, such as proper documentation, can be especially challenging in settings of forced displacement, which can then undermine access to social assistance (such as in Lebanon or Jordan for Syrian refugees) (Gressmann 2016; Mahmood 2017; UNHCR and WFP 2017). Furthermore, displacement for adolescents comes with huge disruption to their education and employment prospects, as well as increased risks of poor psychosocial outcomes and sexual and gender-based violence for girls due to intersectional inequalities (Jones, Pincock and Abu-Hamad 2021). This is not a matter to be overcome with simple social assistance, as in situations of protracted displacement, displaced children face multidimensional vulnerabilities and needs that extend beyond the material, and that often fall between the cracks of the developmenthumanitarian nexus. Indeed, their intersecting inequalities result in exclusion from access to education, health, and other basic services (Abu-Hamad et al. 2019; Jones 2021; Jones, Pincock and Yadete 2021). This has implications for what constitutes 'inclusive and effective assistance' in this context for children and adolescents.

Risks and vulnerabilities faced by children and adolescents often push them to resort to negative coping mechanisms such as children's harmful work (due to higher responsibilities), enrolment in armed groups, sexual exploitation or forced separation (Amar et al. 2019). The undermined basic/public services (e.g. education, health care, child protection) in situations of crises increase their vulnerabilities, such as in Mali, where children have difficulty in accessing child protection services due to a lack of (or poor quality) services as a result of the conflict (Zoungrana 2017), or in Yemen, where the security risks of going to school (with school buildings often destroyed, used to host IDPs, or occupied by armed groups) can be greater than the benefits received there, such as school feeding programmes (Gressmann 2016).

Children and adolescents are in special need of assistance, but they need tailored support that can respond to the crisis dynamics and that is sensitive to the varying risks that different groups of children face in these contexts (e.g., social assistance that takes into account the higher expenses of families with adolescents with disabilities) (Plan International 2020; Presler-Marshall, Jones and Odeh 2020).

\subsection{Risks}

Even though many of the providers of social assistance (e.g., international agencies) are reluctant to give cash to people under 18 (Alliance for Child Protection in Humanitarian Action 2016), in crises situations many children and adolescents are working to support their families and handling cash already. Excluding them from programming can put them, and those in their care, at further risk of resorting to negative coping strategies (IASC 2020). State-led social assistance in FCAS is less likely to directly target children and adolescents, with a few exceptions (such as Libya's universal child allowance) (International Policy Centre for Inclusive Growth 2018).

A handful of guides and toolkits report on children's and adolescents' safeguarding and protection risks when navigating access to social assistance, not necessarily linked to sound evidence, often focusing on cash and vouchers. As cash and voucher assistance is often highly desirable in these contexts, families may try to meet the targeting criteria (or conditions), even if that means harming or neglecting some children (Amar et al. 2019).

Indeed, social assistance can often focus on younger children but not have adolescent-specific conditionalities, such as in Plan International's conditional cash transfer (CCT) in the Central African Republic (CAR), which monitored the health of unaccompanied and reunified infants and children from birth to age nine as part of the conditions for families to receive the cash transfer (but not older children) (Plan International 2020; Plan International and Women's Refugee Commission 2020). Harm can result from physical, emotional, or sexual abuse that may result from work itself (e.g., physical harm caused by carrying 
heavy building materials) or the environment (e.g., placing children in proximity to other community members or staff who may abuse them) (Save the Children 2019). Children who are direct recipients of assistance or who accompany adults to collect cash or vouchers or have to travel to markets to spend the transfer can be exposed to attacks or theft (ibid.). By their very nature, educational activities in conflict-affected contexts can place children at increased risk (Nicolai and Triplehorn 2003). Schools may be targets of attacks (as in many cases schools represent state authority), while gathering school-age children together to teach them may offer easier opportunities for military recruitment than when children are dispersed. The importance of education to conflict-affected communities may be such that the prospect of schooling splits up families that might otherwise stay intact, or the educational expenses may leave children with little alternative but to put themselves at risk, through sex work, for example (Dunne, Humphreys and Szyp 2021; Justino 2014; Nicolai and Triplehorn 2003; Pereznieto, Magee and Fyles 2017).

Social norms can also become barriers that different groups of children must overcome to access assistance, such as girls, who face restrictions on their mobility in Yemen, for example (Gressmann 2016), or genderbased violence in DRC and CAR (IRC, Save the Children and Catholic Relief Services 2017; Plan International 2020; Plan International and Women's Refugee Commission 2020). Programmes that single out specific children for assistance can generate stigma against them and their families, such as the support for children born of sexual violence in Iraq (who are often stateless and denied access to different forms of social assistance), which increased community animosity towards them (Neenan 2017). The risk of harm can also arise from any conditions imposed on the social assistance (e.g., around school attendance or work) where it may not be designed and implemented in a nuanced and locally appropriate way (Sumberg and SabatesWheeler 2020).

Digitisation has, in some contexts, tried to reduce some of these risks, such as in Uganda, where girls receiving cash from Plan International expressed concerns about the delivery mechanism and preferred mobile money because of its low visibility (McAteer 2020; Plan International 2020). Technologies can also bring new, complex, and constantly changing risks to children's and adolescents' safety, which create ethical dilemmas for providers of social assistance. Children who are vulnerable offline are also likely to be vulnerable online (e.g., to exclusion, data misuse), particularly girls, LGBTQI+ youth, and migrant and displaced children.

\subsection{Outcomes}

During a crisis, children and adolescents can benefit from social assistance directly or indirectly (when provided to an adult as a household or individual-level assistance). There is abundant literature on the positive outcomes of social assistance for children's and adolescents' lives, particularly the case for social transfers (mainly cash transfers), but also around public works programmes.

It is nevertheless important to note that the quality, access, and adequacy of supply of services (often undermined in FCAS) linked to (or integrated into) social transfers affect the extent to which these programmes are effective. Furthermore, conditionalities in contexts where basic services are weak or fragmented might result in more deeply entrenched vulnerabilities. Indeed, a cash and voucher assistance programme that delivered 'labelled' unconditional cash transfers to caregivers of children and adolescents aged 6-16 in Lebanon experienced a 'ceiling effect' on the impact of enrolment because of supply-side constraints in the number of spaces available in schools for interested students (de Hoop et al. 2018; Plan International 2020).

In FCAS, particularly where there are large numbers of skipped-generation households, such as in Uganda with the Senior Citizen Grant, transfers made to older people were highly beneficial for children and their nutrition (Dietrich et al. 2017; Merttens et al. 2016; UNDESA 2018). Regular cash transfers have also mitigated the detrimental impacts of lingering civil conflict on children's nutritional status in Yemen on a large scale through the Social Welfare Fund (Ecker et al. 2019).

However, adults receiving social assistance does not necessarily translate into positive outcomes for children and adolescents. Sometimes the outcomes are mixed and can vary across groups of children and depend on intersectional characteristics. In a WFP programme in Niger that delivered CVA to families with adolescents, levels of anaemia among boys decreased while they increased among girls, possibly due to girls' menarche during the pilot (Pirola, Mbeng and Jenkins 2018; Plan International 2020). The study hypothesised that this 
was due to the impact of the initiation of menstruation, and that boys tend to purchase meat-based snacks, while girls are more likely to purchase non-food items, leading to poor consumption of iron-rich foods (Pirola et al. 2018).

Public works programmes deserve a separate mention, as the provision of assistance is conditional on the provision of labour. Research on this programme modality has highlighted outcomes particularly on the quality of childcare, child wellbeing, and child work. Research on a public works programme in Rwanda highlights that the programme can compromise carers' ability to provide high-quality care, and how childcare services at the work site or the establishment of wider community-based childcare mechanisms can enable improved impact on child wellbeing, quality of care, and family separation and reunification (Roelen and Shelmerdine 2014). Design features meant to increase women's empowerment can instead amplify girls' disadvantages. Specifically, by targeting women in public works programmes, who often care for children, girls may be forced to leave school (Presler-Marshall and Jones 2018). Tafere and Woldehanna (2012) found that Ethiopia's Productive Safety Net Programme (PSNP) increased girls' time spent on both paid and unpaid work. However, an increase in children's work does not represent a risk by nature, and additional monitoring and evaluation mechanisms should be used to understand whether children's work (prior to or as a result of social assistance) is in fact harmful to them or not.

The time that children and adolescents allocate to work responsibilities can also be altered by direct provision of social transfers to them, which can in turn reduce associated risks of violence or exploitation derived from that work. Girls receiving cash assistance in Somalia reported a reduction in their work outside the home, thus limiting the distance they needed to travel, reducing potential threats of violence from outside the home (Women's Refugee Commission and Adeso 2018).

Much of the literature is economically oriented, and it analyses improvements in the assumed trade-off between children's education and work, suggesting that providing cash to offset the real and opportunity costs of educating children can reduce child labour (Dammert et al. 2018; de Hoop and Rosati 2014). Labour is often treated as a 'black box', with no attempts to provide nuanced understandings or to separate harmful from not-harmful children's work or address the potential harms of schooling. For example, an evaluation of Pakistan's Female School Stipend Programme highlights reduced girls' labour force participation from 9 per cent to 5 per cent (Alam et al. 2011; Presler-Marshall and Jones 2018).

If children and adolescents are direct beneficiaries of social assistance during crises, outcomes are not necessarily always positive, and coercion or violence by those who want access to their cash is a common concern in the literature, particularly for those facing intersecting inequalities. The International Rescue Committee (IRC) reports on a cash transfer programme for adolescent girls in DRC that generated jealousy among non-beneficiaries, explaining that girl recipients felt coerced to use the cash for family expenses rather than for their own needs, as was intended (IRC et al. 2017).

On the other hand, in cultures where sharing is routine and common, social assistance can also be used as an asset - that is, as a source of social cohesion, where beneficiaries cooperate with non-beneficiaries, such as in the Plan International CVA programme in Uganda (McAteer 2020; Plan International 2020).

In some contexts, due to the short duration of programmes, their impacts and outcomes are also short-lived, such as in a World Vision cash-for-food programme in Iraq, with children and adolescents going back to work when the assistance ended (World Vision Iraq 2018).

Lack of access to social assistance for children and adolescents can expose them to physical, sexual, and/or emotional violence (UNICEF 2020; World Vision 2020), such as in Mali, where boys were pushed into joining armed groups in a context of no access to schooling (and school meals); or adolescent girls being sexually exploited due to lack of access to livelihood support (Plan International 2018, 2020; Women's Refugee Commission 2014). 


\section{Youth}

Table 5.1 highlights and introduces the main findings for this marginalised group in terms of risks (predistribution, during, and post-distribution) and outcomes (positive and negative of receiving or not receiving social assistance) of navigating access to social assistance.

\section{Table 5.1: Summary of findings relating to youth}

\begin{tabular}{|c|c|c|}
\hline & & Youth \\
\hline \multirow{3}{*}{$\begin{array}{l}\text { Known risks of } \\
\text { navigating access to } \\
\text { social assistance }\end{array}$} & Pre-distribution & Bias; marginalisation; bribery; violence; neglect \\
\hline & Distribution & Insecurity; violence \\
\hline & Post-distribution & Violence; stigma; labour competition; debt \\
\hline \multirow{2}{*}{$\begin{array}{l}\text { Outcomes of not } \\
\text { receiving social } \\
\text { assistance }\end{array}$} & Positive & No positive effects identified \\
\hline & Negative & Discrimination; violence; social tension; alcoholism; humiliation \\
\hline \multirow[t]{2}{*}{$\begin{array}{l}\text { Outcomes of receiving } \\
\text { social assistance }\end{array}$} & Positive & $\begin{array}{l}\text { Labour market outcomes; reduced tensions and violence; enhanced } \\
\text { education; improved soft skills }\end{array}$ \\
\hline & Negative & Stigma; vulnerability; violence; sexual exploitation; migration \\
\hline
\end{tabular}

\subsection{Needs}

In the contexts of crises, many policies and programmes are designed and implemented by prosperous people and older generations (e.g., the non-poor elite, elder leaders) with little attention or consideration to the views, needs or preferences of vulnerable youth (Bukenya and Yanguas 2013; Golooba-Mutebi 2004). This is the case for societies with high inequalities at the outset that affect youth, which can result in their exclusion from social assistance (Ezcurra and Rodríguez-Pose 2009), such as in Sierra Leone, with youth more likely to resort to violence (Bangura 2016).

Around the world, young people are disproportionately affected by unemployment, and fragility means it is even more challenging for them to gain access to work, with lower quality jobs for those who do find work. This results in growing labour market inequalities, disrupted school and work trajectories, and youth being pushed to engage in jobs that are informal, unstable, underpaid or even high-risk and harmful - just for daily survival.

Intersectionality also plays a role in determining young people's needs in FCAS, with young women in particular more likely to be withdrawn from education and prevented from working outside of the home, due to a combination of family fears for their safety and the pressure of conservative social norms.

Much of the literature looks at the links between youth unemployment, fragility, and migration, and its vicious cycle in FCAS (Decent Jobs for Youth 2018). Social assistance (especially social transfers, livelihood programmes, and cash-for-work programmes) among young people in these contexts may have an explicit objective of fostering economic opportunities and/or building peace, and thus breaking that cycle.

\subsection{Risks}

Social assistance programmes in FCAS are highly likely to face corruption (e.g., bribery), unfair selection of beneficiaries (e.g., those with good connections), or politicisation during elections, which can exclude vulnerable young people or intensify their vulnerabilities. State employment programmes for youth also risk crowding out the most vulnerable (due to an increase of workers in certain fields) as they fail to address the structural causes of the workers' exclusion. This is the case with informal workers in the states of Kano and Kaduna in Nigeria (Kelly 2019). 
With an intersectional lens, gender dynamics can result in enhanced risks for young women when they navigate access to social assistance. Bribery can be considered a protection risk as it can expose individuals to threats or retaliation if they reject direct requests from figures of authority. In Cameroon, young women shared experiences of village authorities asking for money in exchange for registering them to participate in a cash programme (Freccero et al. 2019). YESSO, a cash transfer programme for young people in Nigeria, used a database compiled by community leaders who had ranked the eligible residents. An assessment of the programme showed that more men than women were involved in the schemes, and that in some schemes, only certain jobs such as hairdressing and petty trading were deemed suitable for women (Banfield 2014; Kelly 2019). The earmarking of medical and socioeconomic services for victims of sexual violence in FCAS - for example, for fistula operations - causes victims with other health problems or non-victims with childbirth-related fistulas to fall outside of the assistance framework. As a consequence, poor women who are operated on for a fistula at childbirth and who are in search of assistance see no other choice and may report it as sexual violence, then having to deal with the resulting social stigma associated with rape (Douma and Hilhorst 2012).

However, literature on cash transfers for youth in FCAS has overlooked notions of stigma and shame (Roelen 2020). There is some evidence from stable contexts, such as in Lesotho and Malawi, which indicates that young people experience stigma and shame as a result of receiving 'free money', and would prefer to work in return for the cash transfer (Ansell et al. 2019). Furthermore, violence is an often-cited risk when navigating access to social assistance by youth in FCAS, with a general climate of fear and insecurity, which also affects cash distribution processes and beneficiaries' safety. In Cameroon, young women frequently cited fear of attack by Boko Haram as a significant protection risk during travel to collect cash from mobile money providers and said that such travel is simply too dangerous and therefore, they send male intermediaries instead (Freccero et al. 2019).

\subsection{Outcomes}

Cash transfers as a stand-alone modality cannot address the legal and policy issues that often constrain youth livelihoods or their access to services (e.g., right to work, access to health and education, etc.) in FCAS. In Afghanistan, the repatriation cash grant has catalysed investments in livelihoods for a small number of beneficiaries, but scarce and poorly paid livelihood opportunities prompted further migration of male youth to Pakistan and elsewhere (Harvey and Pavanello 2018). This is not only the case for cash transfers; public works that target young men, such as in Sierra Leone, have been criticised for being short term and for lacking a vision for long-term sustainability, as well as having limited linkages to longer-term skills or employment structures (Holmes 2009; Holmes and Jackson 2007).

There are some youth-targeted social assistance programmes that result in positive livelihood outcomes such as employment. These often involve cash transfers that are conditional on education/training or the socalled 'cash-plus' programmes. For instance, an evaluation of Jovenes en Accion, a CCT programme in Colombia that provides cash in exchange for enrolment in education for youth aged 14-28 years, finds that it reduces informal employment and improves labour market outcomes among youth (Attanasio et al. 2017). Modalities are particularly relevant in FCAS, where cash partnered with other components ('cash-plus') has become increasingly common. Some programming efforts that target youth rely on the assumption of an employment-peace nexus. This is the case of entrepreneurship grants (one-off transfer), training (combined with social assistance), and other variations of 'graduation' programmes in FCAS, such as with the Youth Opportunities programme in northern Uganda (cash and vocational training) which, four years later, resulted in increased hours of work and earnings (Blattman et al. 2014).

Other assistance focuses on a combination of cash transfers and soft skills training as a way to reduce the risk of further conflict. In Liberia, for instance, the Sustainable Transformation of Youth programme recruited high-risk urban men, such as those engaged in petty crime and drug dealing and offered them an eight-week course of group cognitive behaviour therapy and a cash transfer, which was accompanied by large, sustained falls in crime and violence (Blattman et al. 2017).

Not receiving social assistance (particularly social transfers) can often result in negative outcomes for marginalised young people during crises. In post-conflict contexts, the implications of social divisions and exclusion can be detrimental to the peace process, creating tension between the objective of social 
assistance aiming to reduce poverty, and the underlying objectives of supporting the peace process (Holmes 2009). This is the case in Sierra Leone, where youth faced discrimination and exclusion as they were significantly affected by the eligibility criteria for inclusion in the programme established by the National Commission for Disarmament, Demobilization, and Reintegration. The eligibility criteria were youthunfriendly, specifically targeting combatants who produced weapons and ammunition, while marginalising those who only played support roles. This had implications for the peace-building process in the country and resulted in frustrated youth willing to resort to any means for survival, such as violence (Bangura 2016).

Exclusion from social assistance that challenges gender norms can also result in stigma. This was the case in Karamoja, Uganda, where aid organisations undermined men's role as family providers by giving rations directly to women (including young women), increasing alcoholism among young men in camps for displaced people (Lehrer 2009); their humiliation by soldiers often resulted in them being victims of abuse and violence (Onyango 2012).

\section{Older people}

Table 6.1 highlights and introduces the main findings for this marginalised group in terms of risks (predistribution, during, and post-distribution) and outcomes (positive and negative of receiving or not receiving social assistance) of navigating access to social assistance.

\section{Table 6.1: Summary of findings relating to older people}

\begin{tabular}{|c|c|c|}
\hline & & Older people \\
\hline \multirow{3}{*}{$\begin{array}{l}\text { Known risks of } \\
\text { navigating access } \\
\text { to social assistance }\end{array}$} & Pre-distribution & $\begin{array}{l}\text { Neglect; marginalisation; exclusion; lack of knowledge of providers; lack of } \\
\text { participation in programme design }\end{array}$ \\
\hline & Distribution & $\begin{array}{l}\text { Access issues; missing out on distributions; use of intermediaries; theft; } \\
\text { struggles with technology }\end{array}$ \\
\hline & Post-distribution & Theft; insufficient assistance \\
\hline \multirow{2}{*}{$\begin{array}{l}\text { Outcomes of not } \\
\text { receiving social } \\
\text { assistance }\end{array}$} & Positive & No positive effects identified \\
\hline & Negative & $\begin{array}{l}\text { Food insecurity; being forced to beg; substandard accommodation; } \\
\text { deprivation }\end{array}$ \\
\hline \multirow{2}{*}{$\begin{array}{l}\text { Outcomes of } \\
\text { receiving social } \\
\text { assistance }\end{array}$} & Positive & Improved food security \\
\hline & Negative & Frustration; feeling like a burden; inadequate assistance forcing people to beg \\
\hline
\end{tabular}

\subsection{Needs}

During a crisis, older people are among those most at risk due to widespread prejudice on the basis of age as well as discriminatory policies and practices, yet little is known about their particular experiences (Amnesty International 2020: 15; McGivern and Bluestone 2020: 4; Sheppard et al. 2018: 4). In humanitarian crises, older people are often left behind or reluctant to leave due to their deep ties to their homes, but staying often means facing violence, the absence of family and friends, increased food insecurity, and the loss of services such as health care, housing, electricity, and water supplies (Amnesty International 2020: 6-8, 48; UNHCR 2021: 6).

If displaced, the availability of support resources for older people may be greatly diminished, and/or they may be separated from their family or community (UNHCR 2021: 6). They may go from being independent providers for themselves and any dependants, to being invisible and themselves dependent on assistance, with their traditional power and influence diminished (Amnesty International 2020: 48; Barbelet 2018: v). 
Many older people care for children or other adults, which increases the negative impacts of crises on them (Barbelet 2018: v; McGivern and Bluestone 2020: 16; UNHCR 2021: 6). Older people who have a disability, belong to ethnic, religious, or linguistic minorities, or identify as LGBTQI+ may face added layers of discrimination, stigmatisation, and harassment in addition to the specific challenges associated with being older (UNHCR 2021: 7). For example, older women were found to have worse access to services and income than men while being more likely to be caring for others or on their own (McGivern and Bluestone 2020: 6).

Older people often lack access to humanitarian responses to crises, facing serious barriers to humanitarian assistance. Their basic needs are often unmet, and their rights denied (McGivern and Bluestone 2020: 8; Robinson et al. 2020: 44).

Research with older people in Lebanon, South Sudan, and Ukraine also found that almost half of the study sample felt anxious, hopeless, or depressed most or all of the time (McGivern and Bluestone 2020: 13). Older people's increased dependency on others during crises also increases their risk of experiencing violence, neglect, and abuse (ibid.: 15).

\subsection{Risks}

\subsubsection{Pre-distribution}

A lack of information about older people's needs and capabilities makes it harder to support their specific needs during crises, and many older people feel that they do not know enough about the assistance that is available to them (Barbelet 2018: 17; McGivern and Bluestone 2020: 14). There is an inaccurate assumption that all older people live with and are supported by other family members, whereas many actually live alone or are household heads (Amnesty International 2020: 51; McGivern and Bluestone 2020: 5).

Registering for assistance can also be a challenge. In Nigeria, for example, many older people in camps had never been registered or found themselves inexplicably removed from registration lists, meaning they did not receive any food assistance (Amnesty International 2020: 8, 53-4). Older people seem to be disproportionally affected by these registration issues and older women, in particular, have struggled to resolve these issues (Amnesty International 2020: 8-9, 54). None of the assistance received specifically targeted them as older people (ibid.: 51 ).

\subsubsection{Distribution}

Older people face difficulties when it comes to the distribution of social assistance and many of them struggle to reach distribution points independently, especially if they have a disability or are very elderly (McGivern and Bluestone 2020: 6, 19). Older people are particularly at risk of missing out on distributions in the early stages of responses, before arrangements for support for collection by friends, family, and volunteers can be made (ibid.: 19). Relying on others can result in older people being taken advantage of (Freccero et al. 2019: 699).

Older people are often not prioritised at distribution or registration sites and feel they cannot 'fight' with young people in the lines (Amnesty International 2020: 51, 62; Barbelet 2018: 19). Having to stand in lines for a long time can be very challenging and discourage them from returning (Barbelet 2018: 20). Technological illiteracy can make assistance distributed via mobile money challenging for older people and increase the possibility that they will be taken advantage of (Freccero et al. 2019: 700).

Displaced older people have very little access to livelihoods, which makes them heavily dependent on assistance. If the amounts provided are inadequate, they are forced into negative coping strategies such as reduced food consumption and begging (McGivern and Bluestone 2020: 8).

\subsubsection{Post-distribution}

Older women have been particular targets for theft as a result of their participation in cash programming in Cameroon, for example, while in Afghanistan, their needs were so great that they often spent their entire disbursement as soon as the cash was acquired (Freccero et al. 2019: 700, 707). Very few older people reported knowing how to formally voice their opinion or make a complaint about the services being provided to them (McGivern and Bluestone 2020: 5). 


\subsection{Outcomes}

Not receiving social assistance, or not receiving enough social assistance, forces older people to rely on negative coping mechanisms such as begging or severely reduced food consumption (Amnesty International 2020: 54). Older people have fewer livelihood opportunities, which means they are very reliant on assistance for shelter and other basic needs. In camps for displaced people in Nigeria, for example, it means that older people are living in sub-standard accommodation, and face poverty and food insecurity (ibid.: $50,53,60$ ).

Social assistance can ensure that older people get food and other basic needs for themselves and their dependants. However, the receipt of social assistance can be difficult for them, especially if they were living independently before the crisis, and can make them feel like a burden (ibid. 2020: 49, 51). The lack of attention to older people's specific needs means that food and other types of assistance are often not appropriate (for example, food that is easy to eat and digest), which means the assistance is not as effective as it could be (Barbelet 2018: 20-21).

\section{People with disabilities}

Table 7.1 highlights and introduces the main findings for this marginalised group in terms of risks (predistribution, during, and post-distribution) and outcomes (positive and negative of receiving or not receiving social assistance) of navigating access to social assistance.

\section{Table 7.1: Summary of findings relating to people with disabilities}

\begin{tabular}{|c|c|c|}
\hline & & People with disabilities \\
\hline \multirow{3}{*}{$\begin{array}{l}\text { Known risks of } \\
\text { navigating } \\
\text { access to social } \\
\text { assistance }\end{array}$} & Pre-distribution & $\begin{array}{l}\text { Neglect; discrimination; lack of access; lack of knowledge of providers; lack of } \\
\text { accessible information; lack of participation in programme design }\end{array}$ \\
\hline & Distribution & $\begin{array}{l}\text { Access issues; missing out on distributions; attitudinal barriers; use of } \\
\text { intermediaries; theft; sexual exploitation and abuse; gender-based violence }\end{array}$ \\
\hline & Post-distribution & $\begin{array}{l}\text { Theft; assistance quickly used up; insufficient assistance; community tensions; } \\
\text { abuse }\end{array}$ \\
\hline \multirow{2}{*}{$\begin{array}{l}\text { Outcomes of not } \\
\text { receiving social } \\
\text { assistance }\end{array}$} & Positive & No positive effects identified \\
\hline & Negative & $\begin{array}{l}\text { Deprivation; poverty; reduced health and education; begging; food insecurity; } \\
\text { sexual exploitation and abuse }\end{array}$ \\
\hline \multirow{2}{*}{$\begin{array}{l}\text { Outcomes of } \\
\text { receiving social } \\
\text { assistance }\end{array}$} & Positive & Improved health and education \\
\hline & Negative & Inadequate assistance leading to hunger and distress \\
\hline
\end{tabular}

\subsection{Needs}

People with diverse disabilities, including newly acquired disabilities, have been found to have a disproportionately negative experience of humanitarian crises and responses, as they are among the most marginalised groups in crisis-affected communities (Handicap International 2015: 8; Holden et al. 2019: 1; Pearce 2015: 460; Rohwerder 2017: 1). During humanitarian crises, people with disabilities experience increased problems due to loss of income and shelter, abandonment or separation from family, loss of support structures, as well as increased dependency on others. They may also suffer from loss of assistive and mobility devices, and experience difficulties accessing information; while discrimination and other barriers disadvantage them further (Amnesty International 2019: 5; Handicap International 2015: 8; Rohwerder 2017: 2). The breakdown of previous support systems and the loss of livelihoods as a result of crises result in increased dependence and a greater risk of exploitation (Rohwerder 2016: 2).

Intersectional inequalities mean that women with disabilities, adolescent girls and younger children with disabilities, and older persons with disabilities are particularly vulnerable to discrimination, exploitation, and 
violence during emergencies, but may have additional difficulties accessing the support and services that could reduce their risk and vulnerability (Holden et al. 2019: 4-5; Pearce 2015: 461; Rohwerder 2016: 2; Rohwerder 2017: 1). Recent research finds that children and adolescents with disabilities remain largely invisible, and especially so in FCAS, and that the ways in which social protection programming can contribute to social justice for them have been relatively neglected (Abu-Hamad et al. 2019; Presler-Marshall et al. 2020). A study from the Overseas Development Institute (ODI) (Jones et al. 2016) has also highlighted that the increased needs of people with disabilities often emerge not from their disability but due to the social exclusion that arises from it.

People with disabilities often have difficulties accessing humanitarian response and basic services, despite policies for their inclusion (Amnesty International 2019: 6; Handicap International 2015: 4, 18; Holden et al. 2019: 5; Robinson et al. 2020: 41). The main barriers to accessing humanitarian assistance in crisis contexts include: lack of accessible information about services; the difficulty in accessing services due to lack of physical or financial access; limited staff knowledge, attitudes, and practices in relation to disability inclusion; distance from services; lack of data on disability; gaps in policy development and implementation; and negative attitudes of family members and communities (Handicap International 2015: 4; Rohwerder 2017: 2).

The variety of barriers to accessing humanitarian assistance programmes increases the risks for people with disabilities, including the risk of violence, abuse, and exploitation (Pearce 2015: 460; Rohwerder 2017: 2). Women and girls with disabilities - especially those with intellectual and psychosocial disabilities - are especially vulnerable to sexual and gender-based violence during crises (Holden et al. 2019: 4-5; Rohwerder 2016: 6). Dependence, isolation, stigma, and lack of social connections increase the risk of violence and exploitation for people with disabilities (Pearce 2015: 468-9).

\subsection{Risks}

\subsubsection{Pre-distribution}

The lack of disability-disaggregated data in crisis situations renders people with disabilities programmatically invisible and affects their access to social assistance, with their specific needs not taken into account (Amnesty International 2019: 6; Holden et al. 2019: 8). Disability stigma, negative attitudes towards disability, and other concerns can mean that 'families may not disclose, or may hide, relatives with a disability, making it difficult for humanitarian actors to identify them and respond to their needs' (Holden et al. 2019: 7; Rohwerder 2016: 11).

Social and cultural norms that devalue the lives of people with disabilities may lead to their deprioritisation by communities in humanitarian settings, and result in harmful and neglectful practices such as not advocating for their inclusion in programmes (Holden et al. 2019: 7).

Many people with disabilities struggle to access the social assistance they need (Handicap International 2015). Lack of accessible information about what is available also hinders their access to assistance (Handicap International 2015: 13; Holden et al. 2019: 5). The design of programmes can be exclusionary and inappropriate - for example, cash- or food-for-work programmes where the work is not accessible to people with disabilities (Holden et al. 2019: 5). Research with adolescents with disabilities in Jordan and Palestine found that government and UNHCR cash transfer programmes meant to stave off poverty and food insecurity 'denied them benefits because they were inadequately targeted to include those with disabilities' (PreslerMarshall et al. 2020: 523).

\subsubsection{Distribution}

The location of distribution points is a major barrier for people with disabilities as many are too far away and not affordable to get to, or accessible (Handicap International 2015: 14; Sheppard et al. 2018: 5). Lack of affordable or accessible transportation in different contexts has been found to make people with disabilities more vulnerable to exploitation, and they often have to give money or a portion of their rations to people who help transport their food aid for them (Amnesty International 2019: 22; Pearce 2015: 471).

Further accessibility issues exist at distribution points, including negative attitudes of staff (Holden et al. 2019: 6; Sadat 2018: 1). Institutional barriers to accessing social assistance include being required to be physically present, lack of prioritisation during distributions, and invisibility (Sheppard et al. 2018: 8, 24). Intermediaries may not be allowed to receive assistance on behalf of people with disabilities, or use of intermediaries may 
increase the risk of theft and delay the recipient actually receiving assistance (Amnesty International 2019: 22; Freccero et al. 2019: 699).

In Uganda, women and girls with disabilities were identified as being especially vulnerable to sexual exploitation and abuse when accessing aid (Potts et al. 2020b: 12).

\subsubsection{Post-distribution}

People with disabilities have had their social assistance stolen at times, either from their homes or when collecting it (Sheppard et al. 2018: 8). People with disabilities often struggle financially due to the barriers they face to earning a livelihood and the added cost of disability, which impacts how their assistance is used and often means they spend their entire disbursement as soon as they receive it (Freccero et al. 2019: 707; Potts et al. 2020b: 20). For example, a person with disabilities may need to use a larger portion of their assistance to pay for transportation or assistance to reach the market or for specific items that are scarce. This could also be coupled with risk of exploitation (Holden et al. 2019). Social assistance programmes often do not account for the added costs that may accompany disability (Presler-Marshall et al. 2020). Social assistance can cause additional stigma and negative attitudes towards people with disabilities (Freccero et al. 2019: 708; Sheppard et al. 2018: 24). Accountability mechanisms are not always accessible to people with disabilities (Sadat 2018: 1).

\subsection{Outcomes}

People with disabilities have less access to financial resources and economic opportunities but often have needs that involve additional costs for them and their households, such as transportation, health and medical services, special food, or additional clothing, blankets, and hygiene and sanitary items, which can drive them deeper into poverty and lead to malnutrition and hunger if they do not receive sufficient social assistance (Amnesty International 2019: 7; Pearce 2015: 473; Presler-Marshall et al. 2020). Lack of social assistance can result in them turning to negative coping mechanisms such as begging or survival sex to survive (Amnesty International 2019: 22; Pearce 2015: 468).

Social assistance can go some way to addressing the needs of people with disabilities during crises. In Yemen, for example, financial support from the government helped to improve the health of some people with disabilities and enabled children with disabilities to go to school, although this support was subsequently interrupted by the worsening crisis, leading to a deterioration in their lives (Amnesty International 2019: 7).

However, if the social assistance provided is not enough to meet their needs, people with disabilities will continue to struggle. In Tanzania, for example, older people with disabilities found the food assistance inadequate so they were going hungry and experiencing physical and emotional distress (Sheppard et al. 2018: 25).

\section{Ethnic and religious minorities}

\subsection{Ethnic and religious minorities: classification challenges}

Historically. many conflicts have resulted either partially or mainly from tensions arising between different ethnic or religious minorities. Because in many societies these two groups are deeply intertwined, and the risks that minorities face are due to them being a minority (religious or ethnic), we will review the evidence for both groups on the whole. This is also due to the challenges in the literature arising from concepts such as castes, clans, sects, and others, which can lead to misclassification and misunderstandings. For the purpose of this paper, we use the terms applied in the literature and evidence.

Table 8.1 highlights and introduces the main findings for these marginalised groups in terms of risks (predistribution, during, and post-distribution) and outcomes (positive and negative of receiving or not receiving social assistance) of navigating access to social assistance. 
Table 8.1: Summary of findings relating to ethnic and religious minorities

\begin{tabular}{|c|c|c|}
\hline & & Ethnic and religious minorities \\
\hline \multirow{3}{*}{$\begin{array}{l}\text { Known risks of } \\
\text { navigating } \\
\text { access to social } \\
\text { assistance }\end{array}$} & Pre-distribution & Marginalisation; discrimination; neglect; elite capture \\
\hline & Distribution & Violence; discrimination; marginalisation; neglect; informal work \\
\hline & Post-distribution & Social injustice; 'impartiality' undermining monitoring \\
\hline \multirow{2}{*}{$\begin{array}{l}\text { Outcomes of not } \\
\text { receiving social } \\
\text { assistance }\end{array}$} & Positive & Reduced risk of physical violence, marginalisation, invisibility \\
\hline & Negative & $\begin{array}{l}\text { Undermined health, nutrition, education, and livelihoods; marginalisation; } \\
\text { isolation; stigma; social tension; social inequalities }\end{array}$ \\
\hline \multirow{2}{*}{$\begin{array}{l}\text { Outcomes of } \\
\text { receiving social } \\
\text { assistance }\end{array}$} & Positive & Livelihood resilience; specific needs met \\
\hline & Negative & Persecution; violence; repatriation; repercussions; exclusion; social tension \\
\hline
\end{tabular}

\subsection{Needs}

The same structures and systems that make ethnic and religious minorities vulnerable and exposed can leave them marginalised or excluded from the humanitarian response during crises. These include: their marginalised social position; the location of their homes; their vulnerable occupations; the nature of their housing; and the language they speak. Intersecting and multiple forms of discrimination, where ethnic- and religious-based discrimination crosses with gender, age and (dis)ability, leave some people even more acutely at risk and excluded.

The increasing polarisation of societies, often underpinned by deep underlying and unresolved tensions between majority and minority groups, has made ethnic and religious minorities particularly vulnerable to violence, persecution, and displacement, and this polarisation has also influenced how their access to social assistance is mediated. Socioeconomic vulnerabilities can leave these marginal groups often systematically excluded from social assistance even though they are frequently the worst affected, such as the dalit caste in Pakistan during the 2010 floods. Furthermore, due to deeply entrenched discriminatory norms that lead to a separation of resources, ethnic and religious minorities can often be discouraged from accessing them. This can often be coupled with weak implementation of national laws to address discrimination, which impacts access to assistance for these marginalised groups (Nightingale 2013).

Non-state providers (e.g., religious, sectarian) are often very important in the everyday lives of poor people in these marginalised groups and are often formed to directly fill the gap left by the state in FCAS (Haddad 2020). They often operate based on favours, and via a patron-client relationship (Cammett and Issar 2010; Denoeux 1993). Sectarian parties emerge out of a long historical tradition of religious charity - for example, in the Middle East. However, the different ways in which sectarian organisations allocate social benefits follows a political logic (Cammett 2014). In the absence of strong public welfare, these organisations stepped in to provide essential services to their followers, leaving out highly vulnerable minorities in the country.

Crises, and particularly conflict situations that are frequently driven by ethnic- or religious-based discrimination, often turn minorities into refugees and internally displaced persons (IDPs) as they flee from persecution and violence, while individuals or groups may be targeted for their identity or face insecurity during community activities. Ethnic and religious identity is critically important when assessing patterns of displacement and the dynamics of crises, as well as programmatic and policy responses to them. Research in conflict resolution and international peacebuilding has found that remaining 'ethnic or religious blind' can actually undermine equity in the provision of assistance and even exacerbate existing mechanisms of exclusion (Gill 2007; Silva et al. 2009).

\subsection{Risks}

Religious and ethnic minorities can experience discrimination, marginalisation, and exclusion through social assistance provided by state and non-state actors. Laws related to eligibility for identity documents or where people are allowed to live can directly exclude religious and/or ethnic minorities from government-provided 
services. For example, the Rohingya in Myanmar have not been recognised by law as an ethnic minority until recently and have therefore been excluded from citizenship (rendering them stateless) and associated entitlements, social services, and government benefits for a long time (RFA's Myanmar Service 2014; UNDESA 2018). During a (religious- or ethnic-based) conflict, and where the government is a party to that conflict, it can control the provision of assistance in geographic areas where other parties to the conflict are based (as with the assistance for Muslim groups in the Nargis response in Myanmar) (Avis 2019). As the providers of assistance change, so do the risks these minorities face, with specific threats and barriers (e.g., discrimination) arising once responsibility for social assistance switches from humanitarian to state actors.

Where public funds for social assistance are constrained, non-state welfare providers and brokers of (for example) health fee waivers or public benefits often aid their supporters and end up being subject to elite capture. Indeed, one study found conformity between the sectarian composition of the population in Lebanon and each sect's estimated share of national public spending (Salti and Chaaban 2010).

Because of structural discrimination, ethnic and religious minorities (such as the dalit caste) are often physically excluded from the majority of the population. This can lead to their exclusion from formal datagathering exercises, engagement, and consultation undertaken by government and aid agencies (Amnesty International and Access Now 2018).

Marginalised ethnic minority groups do not have equal access to remote tools such as the internet or devices, which places them at a disadvantage when social assistance relies on digital methods (Office of the High Commissioner for Human Rights (OHCHR) 2020). Additional protections must extend to those groups, including protections for sensitive data.

There is a deeply ingrained view among humanitarian stakeholders that religion is a personal rather than public matter and one that must be avoided in order to maintain their secular disposition (associated with impartiality for many) (Wilkinson 2018). This means that reports by UNHCR and other humanitarian actors do not cover certain key demographic features, particularly understating (and often entirely omitting) the religious affiliations of refugees. Disaggregated data has programmatic benefits for addressing particular vulnerabilities because it can help to identify those people at risk, indicate whether they are able to access and use assistance, and where more needs to be done to reach them (Allouche, Hoffler and Lind 2020; Sphere Association 2018). However, disaggregated data can also put vulnerable groups at increased risk due to (for example) undermined data practices, including access to sensitive data. This is the case for Rohingya refugees who fled Myanmar to Bangladeshi refugee camps due to experiencing violence and persecution in Myanmar. In Bangladesh, UNHCR collected biometric registrations in coordination with the Bangladeshi government to enable distribution of social assistance, data that - as stated by Bangladeshi officials - will be used to help send the Rohingya refugees back to Myanmar (Rahman 2017; Thomas 2018).

\subsection{Outcomes}

Social assistance can play an important role in providing support (income, nutrition, etc.) for ethnic and religious minorities facing poverty and higher levels of disadvantage. Marginalised ethnic and religious minority groups are more likely to depend on schools as a source of free meals for their children and other social services and thus, in the case of school closures due to conflict, disasters or shocks such as Covid-19, are likely to face additional nutritional and health challenges (OHCHR 2020; Rohwerder 2020).

In recognising those higher levels of disadvantage, some countries and organisations have expanded/focused coverage or relaxed prerequisites for the provision of social transfers to these minorities. This was the case in Colombia, for older indigenous people living in extreme poverty, for whom there was a lower age threshold for eligibility for a government cash transfer (Gobierno de Colombia 2020a; UNDESA 2018). Also, in Yemen, the UNICEF Muhamasheen programme used the government's Social Welfare Fund infrastructure to target cash to the most vulnerable group, as well as integrated non-income inputs, services, and linkages to services. In Myanmar, after the 2015 Cyclone Komen, a parallel system was set up specifically to provide relief support (including cash) to marginalised groups - whether led by civil society, as was the case for the Chin, or by international actors, as was seen for Muslims in Rakhine state. However, setting up parallel systems can result in increased feelings of exclusion and deepen the divide between antagonistic social groups (Avis 2019; Desportes 2019). 
The often-purposeful exclusion of religious and ethnic minorities from the provision of social welfare (including cash assistance) by sectarian parties contributes to the construction and consolidation of social inequalities along partisan and ethnoreligious lines. In so doing, it also strengthens social divisions, such as in the case of Lebanon's divided society (Cammett 2015).

Furthermore, in some crisis situations, ethnic and religious minorities may choose to stay invisible and thus voluntarily exclude themselves from social assistance. For example, due to risk of physical violence linked to sectarian tensions and fears of reprisal attacks in Syria, Syrian Christian and Druze refugees often choose not to register with UNHCR (which means they are excluded from any social transfers they would be entitled to) in order to avoid formal refugee camps; instead, they often seek housing in urban centres where they face isolation, stigmatisation, and (perceived or real) discrimination in accessing humanitarian aid and assistance (Avis 2019).

\section{Sexual and gender minorities}

Table 9.1 highlights and introduces the main findings for these marginalised groups in terms of risks (predistribution, during, and post-distribution) and outcomes (positive and negative of receiving or not receiving social assistance) of navigating access to social assistance.

Table 9.1: Summary of findings relating to sexual and gender minorities

\begin{tabular}{|l|l|l|}
\hline \multicolumn{2}{|c|}{} & Sexual and gender minorities \\
\hline $\begin{array}{l}\text { Known risks of } \\
\text { navigating } \\
\text { access to social } \\
\text { assistance }\end{array}$ & Pre-distribution & Marginalisation; neglect \\
\cline { 2 - 3 } & Distribution & Discrimination; violence; marginalisation; stigma \\
\cline { 2 - 3 } $\begin{array}{l}\text { Outcomes of not } \\
\text { receiving social } \\
\text { assistance }\end{array}$ & Post-distribution & Stigma; violence; psychological damage \\
\cline { 2 - 3 } & Negative & Invisibility and autonomy; physical safety \\
\hline $\begin{array}{l}\text { Outcomes of } \\
\text { receiving social } \\
\text { assistance }\end{array}$ & Positive & $\begin{array}{l}\text { Undermined protection, livelihoods, health care, and other basic needs; } \\
\text { stigma; violence; psychological distress; isolation; violence }\end{array}$ \\
\cline { 2 - 3 } & Negative & $\begin{array}{l}\text { Enhanced access to safe services } \\
\text { behavio; physical and sexual violence; coping mechanisms (changing }\end{array}$ \\
\hline
\end{tabular}

\subsection{Needs}

The needs of people with diverse sexual orientation, gender identity and expression, and sex characteristics (SOGIESC) (also referred to as LGBTQI+) have long been absent from the inclusion agenda in crises programming. This is both due to programmes being SOGIESC-blind and to the relative invisibility of diverse SOGIESC communities in crises (Barbelet and Wake 2020; Sida 2010). This is particularly the case for stateled social assistance (in many FCAS, it is still illegal to be gay and LGBTQI+ individuals are prosecuted), as the few recent studies that looked at LGBTQI+-specific vulnerabilities within social assistance focused on humanitarian/emergency situations.

However, LGBTQI+ populations are not homogeneous and have different needs wrought by intersections of socioeconomic resources, gender, race/ethnicity, age, and regional or national location (Dominey-Howes, Gorman-Murray and McKinnon 2014), which impacts access to social assistance - a fact often overlooked by the little evidence available. The term 'double marginality' has been coined to highlight how the effects of being both LGBTQI+ and a refugee are not simply the cumulative sum of belonging to both groups, but rather, that these marginalisations are compounded, yielding profound distancing from traditional support systems and resources (Buscher 2011). 
The social marginalisation that LGBTQI+ people experience can be exacerbated by the need for official registration while seeking assistance - which can include scrutiny of documents, assignments to gendersegregated facilities, and public reporting of private information - in systems that do not accommodate diversity with regard to sexual orientation and gender identity (SOGI). In Pakistan, on the order of the Supreme Court, separate codes for persons with disabilities and transgender persons were introduced recently by the Bureau of Statistics. Until then, there had been no option available for people to identify as transgender; instead, many people previously identified themselves in the census as a person with disabilities (Gender in Humanitarian Action Asia and the Pacific Working Group 2017). Considerations specific to LGBTQI+ populations (beyond binary gender-sensitive programming) are important in emergency response and more generally in social assistance planning.

Sexual and gender minorities face particular needs and increased vulnerability during conflict and disasters. The impact of emergencies on social infrastructure varies depending on what existed - formally or informally - before the crisis, how the emergency affected the population, and how relief and recovery plans altered the availability of services. Crucial aspects of social support for LGBTQI+ people include communication networks and the physical proximity of emergency-affected populations to their previous survival systems, such as supportive neighbours, friends, family, and organisations offering safe spaces for LGBTQI+ persons (Rumbach and Knight 2014). Private spaces are important for LGBTQI+ wellbeing since minority sexual and gender identities are often publicly concealed and privately expressed. In Haiti, for example, the loss of homes, neighbourhoods, community meeting places and HIV and AIDS service spaces due to the 2010 earthquake disproportionally affected the emotional, physical, and social wellbeing of LGBTQI+ people (International Gay and Lesbian Human Rights Commission 2011).

As well as destruction of infrastructure, the structural limitations that exist for LGBTQI+ persons in emergency situations include: issues of documentation (for instance, despite Pakistan's recognition of a third gender, transgender people are unable to get supporting documents to confirm their identity); the collapse of normal coping mechanisms; and the destruction of informal economies that can buoy security by providing economic stability (Rumbach and Knight 2014). The discrimination and marginalisation that LGBTQI+ people experience can result in exclusion from formal economic activities, including lack of access to employment. For these and other reasons, LGBTQI+ people may engage in informal economic activities across a variety of sectors - whether casual informal work, or sex work via a brothel system or as an individual enterprise. When emergencies occur, normal access to informal work, including sex work, can be severely disrupted. In Nepal, metis (male-bodied, feminine-presenting people) expressed that the money they earned dancing and doing sex work secured their social status within their households, and the loss of that money due to flooding and subsequent forced displacement resulted in increased discrimination and marginalisation within their families (ibid.). Discrimination against metis and their families has been reported during relief distribution and relocation, including metis being told they were not 'full' or 'real' people deserving of the amount of aid given to non-metis (Knight 2017).

\subsection{Risks}

There is a dearth of knowledge within national, international, and non-governmental organisations (NGOs) about LGBTQI+ issues, and about LGBTQI+ concerns specific to crises, such as security, food distribution, housing, toilet facilities, sensitive health care, trauma counselling, repatriation, and family unity and reunification. This lack of institutional capacity, coupled with a lack of training of officials, staff, and volunteers working with LGBTQI+ populations, can further stigmatise, marginalise, and ultimately exclude LGBTQI+ persons from social assistance during crises. Because of this side-lining, LGBTQI+ people can experience increased physical insecurity and psychological distress (Rumbach and Knight 2014).

Social side-lining of LGBTQI+ persons occurs both prior to and during crises due to harmful legal regimes and religious, cultural, and societal stigma towards perceived non-normative sexual orientations and gender identities. This was the case in the Philippines during the Typhoon Haiyan response, where same-sex partners were unable to access relief as 'heteronormative assumptions about what constitutes a family meant that people who lived outside of those norms - for example people in same gender relationships - were deprioritised by relief providers' (Barbelet and Wake 2020; Edge Effect et al. 2018). Also, during the $2011 \mathrm{flood}$ relief efforts in Pakistan, hijras (people who are born male, but identify as more feminine, and traditionally undergo castration and live in communities with other hijras under a community leader) were sometimes 
denied access to relief services because their appearance did not match the gender listed on their identity documents (Paulocanning 2011).

Beyond exclusion, there are concerns over violence linked to governments using pretexts (e.g., disease control during the Covid-19 pandemic) to seize power and crack down on LGBTQI+ people. There is some recognition that targeting of social assistance may stigmatise LGBTQI+ persons, exposing these groups to further risks, and so may not be appropriate (UNHCR 2018). That is the case if LGBTQI+ people are visible and identified, particularly in countries where being LGBTQI+ is illegal. In one such country - Uganda - there were raids in LGBTQI+ shelters in Kyengera where some people were arrested and charged for allegedly disobeying coronavirus regulations on physical distancing (Bishop 2020; Edgell et al. 2020; Rohwerder 2020; UN 2021).

There are also concerns about LGBTQI+ people experiencing abuse, marginalisation, and violence from other community members. In Pakistan, during the pandemic, transgender people reported discrimination when trying to access meals from food distribution points. Most of them claim that others dining at these establishments treated them badly, forcing them to look for other means (Hussain 2020). LGBTQI+ women are particularly vulnerable in crises contexts. If collecting social assistance in person in crowded places, they often lack protection from men if violence breaks out, such as in Haiti, after the 2010 earthquake (International Gay and Lesbian Human Rights Commission 2011).

\subsection{Outcomes}

Even though access to social assistance for sexual and gender minorities in crises can result in enhanced access to cash, food, or safe services (not easy to collate from the lack of evidence for this marginalised group), in many cases, negative outcomes arise from receiving support. As well as the public moral scrutiny LGBTQI+ people face - including being blamed for causing natural disasters (including mass animal deaths), tsunamis, and earthquakes, or scapegoated during times of crisis or panic - the official scrutiny of people's bodies, documents, families, and behaviours in crises can put LGBTQI+ people at risk. This includes when people are moving internally or across international borders, living in shelters or camps, and seeking to restore lost income, including in informal economies, which have often been overlooked in terms of their significance in supporting LGBTQI+ people's autonomy and safety (Garcia 2012; Türk 2013).

Due to the scant evidence found on access to social assistance by LGBTQI+ people, we incorporate in the review 'socially protecting' modalities, not necessarily defined as social assistance by BASIC Research. For some bakla in the Philippines, accessing gender-segregated toilets and shower facilities in temporary shelters has been an embarrassing or humiliating experience. Many report they would feel more comfortable using female facilities. The social norm associated with their masculine bodies compels them to use male bathrooms, where they suffer from mockery and harassment (Rumbach and Knight 2014). Some LGBTQI+ experiences of exclusion and harassment in shelters have been documented. In the aftermath of the 2010 Haitian earthquake, LGBTQI+ persons and their families were vulnerable in shelters. Lesbians, bisexual women, and transgender and intersex people living in shelters were subject to gender-based violence and 'corrective rape' (International Gay and Lesbian Human Rights Commission 2011).

On the other hand, not accessing social assistance due to involuntary exclusion can also increase stigmatisation and violence against sexual and gender minorities. Even targeted relief programmes that are well intentioned can have negative impacts on marginalised groups by rendering the services inaccessible. Programmes targeting a specific population, such as women, make assumptions about what it means to qualify as a 'woman' and reinforce definitions of that population. Indeed, social transfer programmes targeting women only have been problematic for transgender people and people (such as gay men) who do not live in a home with a female who qualifies as head of household (ibid.).

The exclusion of sexual and gender minorities from 'socially protecting' modalities of assistance can also result in negative outcomes. During the 2004 Indian Ocean tsunami, in Tamil Nadu, the exclusion of aravanis was documented by Oxfam. Aravanis are also called hijras (see earlier) or jogappas in some areas of India and identify themselves as neither male/man nor female/woman. Facilities designed to exclusively cater for either male or female persons prevented aravanis from using toilets and showers in tsunami evacuation centres, impeding access to basic sanitation services, and causing public humiliation (Rumbach and Knight 2014). 
However, it is also important to note that invisibility and life at the margins of society is not necessarily a life without autonomy on the part of LGBTQI+ people, particularly intersectional minorities. Research with urban refugees has revealed how invisibility can be a deliberate strategy for LGBTQI+ people, who often employ creative strategies to achieve and maintain their safety - including remaining invisible - amid what can be very challenging conditions.

While visibility in terms of being captured in data sets and accessing safe, appropriate services is important, it is equally important to acknowledge that forcing LGBTQI+ people to 'reveal' themselves in various fora can cause harm (ibid.), as was the case for Burmese refugees in Thailand (Moses 2013). Leaving camp environments (whether for refugees or IDPs) may reduce physical threats to the individual but can greatly limit access to critical information and services, as well as important employment and communication networks. Notably, LGBTQI+ refugees living in urban centres do not fare well, either; as well as facing extreme isolation, they experience harassment, discrimination, and physical threats, and may have to change housing often to avoid persecution.

\section{Analysis}

The experiences of marginalised people during crises, relating specifically to the risks they face when navigating access to social (humanitarian) assistance and the positive and negative outcomes of receiving or not receiving social assistance, are an underexplored area. With the caveat that our review was not systematic, and there were time constraints, the existing literature in this area seems to be skewed towards humanitarian assistance rather than government-led social assistance in crisis contexts. Within this, much of the literature uncovered by this review focuses on cash and its outcomes rather than the outcomes of other types of social assistance. There is also less evidence available from crisis contexts than development contexts. For example, a study of evidence on the effects of cash-based interventions in development and humanitarian contexts notes that there are few sex- and age-disaggregated data sets available to assess results on poverty, health, and education in humanitarian contexts (Simon 2019: 1). This limits our understanding of how different modalities may affect the risks and outcomes of different types of social assistance for different groups of marginalised people during crises.

The focus on humanitarian assistance rather than other forms of social assistance during crises means that much of the evidence we reviewed relies on programming that is shorter term. The implication is that longerterm outcomes, such as those seen in development contexts in relation to particular social assistance modalities, and outcomes for particular groups, are harder to verify or may differ in crisis contexts. For example, outcomes of cash assistance provided to women may provide relief in the short term but do not continue for long enough to make a difference to gender norms and women's ability to survive without the assistance provided (Blackwell et al. 2019). Indeed, women in Syria appreciated the cash assistance they received but worried about what would happen when the programme ended (ibid.).

Also, if the literature is focused on the risks marginalised people face in accessing social assistance in humanitarian crises, this may not reflect the same risks they faced before the acute crisis or in its aftermath, when systems are set up to better accommodate them. However, many humanitarian crises have moved beyond this immediate acute phase and are protracted. Research on women's and girls' experiences of sexual exploitation and abuse in aid responses, for example, took place in Lebanon and Uganda - contexts with long-standing humanitarian responses. Here, the risks evidenced by this research not only reflect the acute crisis phase of humanitarian response but also reflect the risks in ongoing/protracted crisis contexts.

In some contexts, humanitarian assistance for some marginalised people, led by external actors, is by its nature different from a government-led response, and this can have different consequences for these marginalised groups. This relates to a greater focus among aid and donor agencies on rights-based approaches, inclusion, and the Agenda 2030 call to 'leave no one behind'. Such approaches are not always shared by governments in crisis contexts, or not for all marginalised people in their countries. For example, sexual and gender minorities and some ethnic and religious minorities are persecuted by their own governments, so their experience of state-led programmes differs from their experience of humanitarian assistance programming led by the international community. Indeed, this is the case for the LGBTQI+ 
community in Uganda or Muslim Rohingya in Myanmar. In such contexts, 'inclusion' may be experienced and talked about in ways that are radically different from aid agency perspectives. On the other hand, there are also some concerns related to humanitarian assistance, and the fact that humanitarian staff operate in a society where sexism, racism, and ableism persist and are sometimes unintentionally reproduced. It is in these contexts where the principles of neutrality and not giving special treatment to some groups (for example) are enforced without acknowledging some people's particular and intensified barriers in accessing support. Further research is needed to more fully understand the different risks and outcomes and the interactions between them when navigating both government and non-government provided social assistance for these marginalised people in different crisis contexts.

There was also a skewed weighting of the literature in relation to some marginalised groups. Most of the literature looking at the outcomes and risks of social assistance during crises was focused on women and girls, as well as on children and adolescents. There was not much literature that looked at the outcomes and risks of social assistance for other marginalised groups such as older people, youth, people with disabilities, ethnic and religious minorities, and sexual and gender minorities. The literature that discussed these other groups tended to be more focused on their general experience of crises and humanitarian assistance more broadly. Lack of recent evidence for certain groups means that our understanding is largely based on outdated research.

Intersectionality analysis in the literature is often superficial or is not systematic, as it tends to focus on only one segment of someone's identity, leading to a simplistic and narrow way to understand how inclusion or exclusion can happen and the multiple risks that these groups face. ${ }^{8}$ Some of this literature considered intersectionality to a certain extent, by including women with disabilities or older people with disabilities, for example. One report noted that older women in Nigeria struggled with both ageism and sexism in a patriarchal society (Amnesty International 2020). The most common intersectional groups in the literature were women and another identity, or disability and another identity, but this focus comes from just a few papers. It perhaps reflects the push over recent years in the humanitarian sector to consider gender and disability, but any focus beyond this level of complexity, towards disaggregating data for other marginalised groups and to understand the context and attitudes towards multiple marginalised identifiers, is still generally lacking. There are acknowledgements that other aspects of people's identity are likely to have an impact too, but little concrete evidence given, perhaps because of the sensitivities and stigma around some of these identities and whether people prefer to remain invisible to try and stay safe (such as sexual and gender minorities or ethnic and religious minorities, especially in countries where they are actively persecuted).

The disruption caused by displacement is a significant factor affecting people's experiences of crises, and forcibly displaced people deserve a separate mention as an aspect of intersectionality. Even though this marginalised group of people was not a stand-alone key group covered in this paper, evidence collated suggests that there is an increasing evidential focus on this group, and its intersections with the other marginalised groups we have identified in this paper. It should be acknowledged that the way this paper is structured, with its focus on specific groups, may contribute to a more limited analysis of intersectionality, although where possible we have drawn out the links between different groups and highlighted that people's identities do not fit neatly into one group but can span them. An intersectional approach to some of the BASIC Research questions could consider what risks and outcomes are experienced when navigating access to social assistance during crises by different groups within each of our focus marginalised people (women, white, black and minority ethnic, disabled, non-disabled, LGBTQI+, religious, younger, and older, etc.). This intersectional approach would not assume that everyone within these diverse groups experiences similar risks and outcomes.

\footnotetext{
${ }^{8}$ Even though intersectionality is considered a key tool to study different categories and how these are created, reproduced, and perpetuated as part of systems of power and inequality (Rodriguez 2018), there is a lack of consensus on clearly defined intersectional methodologies. One of the debates is around the level at which intersectionality is at work (i.e., structural vs individual level). Another one is around what type of research is most suitable. Intersectionality analysis can provide a bottomup approach to research and can be used in qualitative, quantitative, and/or mixed-methods research. Covering varied research areas such as health, sociology, and psychology, in-depth interviews, focus groups, and ethnography remain common methods for intersectional analysis within the qualitative arena (in addition to tools such as concept mapping and deliberative dialogue), whereas regression models and hierarchical linear models (HLM) are among the quantitative tools, which are still used but less frequently (Bailey et al. 2019; Bauer et al. 2021; Christoffersen 2017; Fehrenbacher and Patel 2019; Grabe 2020; Grace 2014; Hankivsky 2012).
} 
Most of the literature we found that looked at outcomes of social assistance during crises focused on the outcomes of receiving social assistance rather than specifically on the outcomes of not receiving it. The outcomes are linked to the risks people are exposed to when accessing social assistance, which are significant depending on the context and the way in which the programme is designed and implemented, although these links are not necessarily made explicit in the literature. There is very little discussion (or comparison) around the risks and outcomes across design and implementation features of different types of support, targeting mechanisms or modes of distribution. When it is discussed, it is often limited to certain groups. Some evidence highlights the benefits of digital approaches in contexts where there is heightened gender-based violence, and adolescent girls prefer digital payment so that their 'beneficiary' status remains less visible. Community-based approaches to targeting are often accompanied by mention of their particular benefits (speedy, grounded, and local) and risks (potential bias from committee resulting in the exclusion of non-represented or stigmatised minorities). Public works studies often look at children's education or labour outcomes, whereas cash transfers are more often linked to their nutrition and health, and the effects of providing shelter facilities on violence against minorities and/or their protection and security.

We have not reviewed the experiences of social assistance of marginalised people in more stable contexts as this was beyond the scope of this paper, although some reviews note that in both universal or highcoverage schemes and schemes targeted at children, older people or disabled people in these contexts, exclusion remains a significant challenge and the benefits are often inadequate ${ }^{9}$ (Kidd 2014: 1; UNDESA 2018: xvi; Kidd 2017). This is the result of a combination of factors, including:

... prejudices held by more powerful members of society, as manifested in discriminatory practices such as institutionalised biases against marginalised people, institutional blindness to the needs of vulnerable groups in the population (such as people with disabilities) and cultural and social practices that de-legitimise claims...

(Kidd 2014: 5)

It is also due to structural disadvantages and limitations in people's capabilities to access schemes and overcome barriers to inclusion (Kidd 2014: 5-6). Policy decisions on coverage and budgets, and challenges caused by the design and implementation of social assistance programmes, can help reinforce the exclusion of marginalised people or contribute to their inclusion (UNDESA 2018: xxi; Kidd 2017). A review of the state of the evidence around cash transfers indicates little focus on or information available about the impact of cash transfers in stable low- and middle-income country contexts on marginalised groups, beyond women and girls (Bastagli et al. 2016). Such dynamics can also be seen at play in FCAS. However, based on the literature reviewed, the risks around accessing social assistance for marginalised people are heightened in such settings, especially as a result of the disruptions caused by crises; the conditions in these countries mean that people's needs are greater, and it is harder to achieve longer-term outcomes due to the unsettled contexts and the often shorter-term nature of the assistance provided. Because the experiences, including needs and risks, of marginalised people in FCAS are highly intensified, programmes in stable contexts that result in 'positive' outcomes might not be replicable in crisis contexts. Also, outcomes considered 'positive' by marginalised people during crises might not be as 'positive' for marginalised people in stable settings if measured in the same way. This requires further research.

\section{Gaps and state of the evidence}

The evidence base is growing but limited, with the reviewed literature focusing on the impacts of humanitarian cash assistance. It consists of a mix of mainly qualitative research, with some quantitative research, and a few mixed-methods papers. Most of the evidence comes from grey literature rather than peer-reviewed academic papers, although more have been published recently. The evidence mainly comes from case studies in a few different countries (e.g., Lebanon, Uganda, Syria, Afghanistan, and Cameroon) and mainly addresses the experiences of women and girls, although some efforts were made to include women with disabilities or older women. Perhaps the focus on the humanitarian assistance aspect of social assistance during crises comes as a result of searching the literature more generally for social assistance modalities in crises and humanitarian contexts, which tended to produce results focusing on humanitarian assistance. More time would have allowed for specific searches of the literature relating to government-

${ }^{9}$ In 2016, close to 68 per cent of older persons received a pension, only 28 per cent of persons with severe disabilities received disability benefits, and only 35 per cent of children enjoyed social protection (UNDESA 2018: xvi). 
provided social assistance programmes in crises and what they have to say about the experiences of marginalised people. However, the evidence of government support for disabled people in Yemen, for example, suggests that such support is affected by the extent of the crisis in the country, as this support was interrupted by the worsening crisis (Amnesty International 2019).

Considering the key issues focused on by the literature reviewed for this paper, there are gaps in knowledge around the risks and outcomes of government-led social assistance, as well as different types of social assistance in crises. There are also gaps in knowledge about the risks and outcomes for older people, youth, people with disabilities, ethnic and religious minorities, and sexual and gender minorities, as much of the current evidence relating to these issues comes from studies that are not focused specifically on the risks and outcomes of social assistance for these marginalised groups (Rohwerder 2021).

\section{Conclusions}

Crises exacerbate existing risks and inequalities for women and girls and other marginalised people, including children and youth, older people, people with disabilities, ethnic and religious minorities, and sexual and gender minorities, leaving them vulnerable to exploitation and abuse. For marginalised people, accessing social assistance during crises carries with it some risks, as well as positive and negative outcomes. Social assistance can improve food security, help households meet their basic needs, reduce stress and household tensions, reduce gender-based violence, improve health, education, and wellbeing, and reduce negative coping mechanisms. However, it can also expose people to violence and risk and may disrupt their social support mechanisms. Such risks - some of which also apply to those who are excluded from social assistance - include neglect, discrimination, sexual exploitation and abuse, increased household and community tensions, gender-based violence, stigma, theft, and accessibility issues. However, these risks do not apply to all marginalised people, all the time, and in all contexts, and are balanced by some of the positive outcomes resulting from access to social assistance. The risks are not fixed; they vary across contexts, between and within intersectional groups, and can be mitigated through a better understanding of them and how they arise from the bottom up.

More evidence is needed to fully understand the risks of accessing social assistance in crises, including both mainstream programmes as well as group-specific schemes, and the outcomes of receiving (or not receiving) it for many marginalised people, particularly people experiencing intersecting inequalities. The largest evidence base in crisis settings concerns the experiences of women and girls in receiving social assistance, particularly humanitarian assistance, with much less attention paid to the experiences of other marginalised people. More needs to be done to understand the experiences of youth, older people, people with disabilities, ethnic and religious minorities, and sexual and gender minorities to effectively mitigate the risks they face in accessing social assistance in crises and to enable safe, dignified, inclusive and (consequently) more effective social assistance programmes.

Policy and programming looking at social assistance during crises currently focus on cash and how to make it work, especially in relation to humanitarian programming. Most evidence and research is linked to cash and voucher assistance or cash transfers (or these in addition to others), whether within humanitarian or social protection contexts. Programmatic documents that outline the risks involved in accessing social assistance are often presented as received wisdoms, based on theories, anecdotes, or possibilities, instead of being clearly supported by evidence that explains where, who, how often, and how serious. This may influence social assistance programming and donors' and governments' views and operations, without a complete or fully accurate picture of what is occurring for different groups. Our review of the literature found that there is not yet an established framework to assess the risks and outcomes for marginalised groups and minorities when navigating access to social assistance (pre-distribution, during, and post-distribution) during crises.

\section{Potential research questions for BASIC Research}

Overarching question:

How and in what circumstances can safe, dignified, inclusive and (consequently) more effective social assistance programmes be supported in protracted crisis contexts? 


\section{Sub-questions:}

1. What are marginalised people's lived experiences when navigating access to social assistance in specific crisis contexts? What are the risks, threats, and barriers of accessing government- and humanitarianprovided social assistance in crises for marginalised people?

2. How and in what circumstances can social assistance during crises be more responsive/inclusive to marginalised people's experiences/perceptions of what enables and constrains safe, dignified, and inclusive protection and support? How does this vary according to intersectional aspects and contextual conditions?

We need a greater understanding of the processes of exclusion in social assistance during crises and the needs of marginalised people in order to ensure that their experiences of social assistance are positive and beneficial. When marginalised people are in desperate situations, they may tolerate risks associated with accessing social assistance in order to go some way towards relieving their situation, yet these risks need not be as great as they often are. It is important to work with marginalised groups in a participatory way to understand their experiences of social assistance during crises and to find out their views and approaches for risk mitigation. A better understanding of their experiences through participatory processes could provide the basis for more effective and inclusive social assistance programming and implementation during crises. 


\section{References}

Abu-Hamad, B.; Jones, N.; Presler-Marshall, E.; Samuels, F. and Gercama, I. (2019) 'Interrogating the Potential of a "Cash Plus" Approach to Tackle Multidimensional Vulnerability in Humanitarian Contexts: The Case of Syrian Refugees in Jordan', in R. Jawad, N. Jones and M. Messkoub (eds), Social Policy in the Middle East and North Africa: The New Social Protection Paradigm and Universal Coverage, Cheltenham: Edward Elgar Publishing (accessed 12 January 2022)

Alam, A.; Baez, J.E. and Del Carpio, X.V. (2011) Does Cash for School Influence Young Women's Behavior in the Longer Term? Evidence from Pakistan, Washington DC: World Bank

Alliance for Child Protection in Humanitarian Action (2016) Field Handbook on Unaccompanied and Separated Children: Inter-Agency Working Group on Unaccompanied and Separated Children, Alliance for Child Protection in Humanitarian Action (accessed 12 January 2022)

Allouche, J.; Hoffler, H. and Lind, J. (2020) Humanitarianism and Religious Inequalities: Addressing a Blind Spot, CREID Working Paper 4, Coalition for Religious Equality and Inclusive Development, Brighton: Institute of Development Studies, DOI: 10.19088/CREID.2020.002 (accessed 12 January 2022)

Amar, J.; Hames, H. and Clifton, N. (2019) Child Safeguarding For Cash and Voucher Assistance Guidance, London: Save the Children (accessed 18 January 2022)

Amnesty International (2020) 'My Heart Is In Pain' - Older People's Experience of Conflict, Displacement, and Detention in Northeast Nigeria, London: Amnesty International (accessed 12 January 2022)

Amnesty International (2019) Excluded - Living With Disabilities in Yemen's Armed Conflict, London: Amnesty International (accessed 12 January 2022)

Amnesty International and Access Now (2018) The Toronto Declaration: Protecting the Right to Equality and Non-Discrimination in Machine Learning Systems, Canada: Amnesty International and Access Now (accessed 12 January 2022)

Ansell, N. et al. (2019) Social Cash Transfers, Generational Relations and Youth Poverty Trajectories in Rural Lesotho and Malawi, Brunel University London (accessed 12 January 2022)

Attanasio, O.; GuarÍn, A.; Medina, C. and Meghir, C. (2017) 'Vocational Training for Disadvantaged Youth in Colombia: A Long-Term Follow-Up', American Economic Journal: Applied Economics 9.2: 13143

Avis, W.R. (2019) Challenges Religious Minorities Face in Accessing Humanitarian Assistance, K4D Helpdesk Report 666, Brighton: Institute of Development Studies (accessed 12 January 2022)

Baird, S.; Ferreira, F.H.G.; Özler, B. and Woolcock, M. (2013) 'Relative Effectiveness of Conditional and Unconditional Cash Transfers for Schooling Outcomes in Developing Countries: A Systematic Review', Campbell Systematic Reviews 9.1: 1-124, DOI: 10.4073/csr.2013.8 (accessed 12 January 2022)

Bailey, J. et al. (2019) 'Getting at Equality: Research Methods Informed by the Lessons of Intersectionality', International Journal of Qualitative Methods 18, DOI: 10.1177/1609406919846753 (accessed 12 January 2022)

Banfield, J. (2014) Winners or Losers? Assessing the Contribution of Youth Employment and Empowerment Programmes to Reducing Conflict Risk in Nigeria, Nigeria Stability and Reconciliation Programme (accessed 12 January 2022)

Bangura, I. (2016) “We Can't Eat Peace”: Youth, Sustainable Livelihoods and the Peacebuilding Process in Sierra Leone', Journal of Peacebuilding \& Development 11.2: 37-50, DOI:

10.1080/15423166.2016.1181003 (accessed 13 January 2022)

Barbelet, V. (2018) Older People in Displacement: Falling Through the Cracks of Emergency Responses, London: Overseas Development Institute (accessed 13 January 2022)

Barbelet, V. and Wake, C. (2020) Inclusion and Exclusion in Humanitarian Action: The State of Play, London: Overseas Development Institute 
Bastagli, F. et al. (2016) Cash Transfers: What Does the Evidence Say? A Rigorous Review of Programme Impact and of the Role of Design and Implementation Features, London: Overseas Development Institute

Bauer, G.R. et al. (2021) 'Intersectionality in Quantitative Research: A Systematic Review of its Emergence and Applications of Theory and Methods', SSM - Population Health 14: 100798, DOI: 10.1016/j.ssmph.2021.100798 (accessed 13 January 2022)

Berg, M. and Seferis, L. (2015) Protection Outcomes in Cash Based Interventions: A Literature Review, UNHCR and Danish Refugee Council (accessed 13 January 2022)

Bishop, A. (2020) Vulnerability Amplified: The Impact of the COVID-19 Pandemic on LGBTIQ People, New York: OutRight Action International (accessed 13 January 2022)

Blackwell, A.; Casey, J.; Habeeb, R.; Annan, J. and Falb, K. (2019) 'Women's Status and Qualitative Perceptions of a Cash Assistance Programme in Raqqa Governorate, Syria', Gender \& Development 27.2: 253-71, DOI: 10.1080/13552074.2019.1624047 (accessed 13 January 2022)

Blattman, C.; Fiala, N. and Martinez, S. (2014) 'Generating Skilled Self-Employment in Developing Countries: Experimental Evidence from Uganda', The Quarterly Journal of Economics 129.2: 697-752

Blattman, C.; Jamison, J.C. and Sheridan, M. (2017) 'Reducing Crime and Violence: Experimental Evidence from Cognitive Behavioral Therapy in Liberia', American Economic Review 107.4: 1165-1206, DOI: 10.1257/aer.20150503 (accessed 13 January 2022)

Bukenya, B. and Yanguas, P. (2013) Building State Capacity for Inclusive Development: The Politics of Public Sector Reform, ESID Working Paper No 25, Manchester: Effective States and Inclusive Development Research Centre (accessed 13 January 2022)

Buller, A.M. et al. (2018) 'A Mixed-Method Review of Cash Transfers and Intimate Partner Violence in Low- and Middle-Income Countries', World Bank Research Observer 33.2: 218-58 (accessed 13 January 2022)

Buscher, D. (2011) 'Unequal in Exile: Gender Equality, Sexual Identity and Refugee Status', Amsterdam Law Forum 3.2: 92-102 (accessed 13 January 2022)

Cammett, M. (2015) 'Sectarianism and the Ambiguities of Welfare in Lebanon', Current Anthropology 56.S11: S76-S87, DOI: 10.1086/682391 (accessed 16 January 2022)

Cammett, M. (2014) Compassionate Communalism: Welfare and Sectarianism in Lebanon, Ithaca NY: Cornell University Press (accessed 16 January 2022)

Cammett, M. and Issar, S. (2010) 'Bricks and Mortar Clientelism’, World Politics 62.3: 381-421 (accessed 16 January 2022)

Christoffersen, A. (2017) 'Intersectional Approaches to Equality Research and Data', Research and data briefing, Equality Challenge Unit (accessed 16 January 2022)

Crenshaw, K. (1989) 'Demarginalizing the Intersection of Race and Sex: A Black Feminist Critique of Antidiscrimination Doctrine, Feminist Theory and Antiracist Politics', University of Chicago Legal Forum 1989.1: 31

Cross, A.; Manell, T. and Megevand, M. (2018) Humanitarian Cash Transfer Programming and GenderBased Violence Outcomes: Evidence and Future Research Priorities, International Rescue Committee and Women's Refugee Commission (accessed 16 January 2022)

Dammert, A.C.; de Hoop, J.; Mvukiyehe, E. and Rosati, F.C. (2018) 'Effects of Public Policy on Child Labor: Current Knowledge, Gaps, and Implications for Program Design', World Development 110: 104123, DOI: 10.1016/j.worlddev.2018.05.001 (accessed 16 January 2022)

Decent Jobs for Youth (2018) 'Youth in Fragile Situations: Promoting Youth Employment for Peace and Resilience', Decent Jobs for Youth (accessed 16 January 2022)

de Hoop, J. and Rosati, F.C. (2014) Cash Transfers and Child Labor, New York: Oxford University Press on behalf of the World Bank (accessed 16 January 2022) 
de Hoop, J.; Morey, M.; Ring, H.; Rothbard, V. and Seidenfeld, D. (2018) 'Min Ila' Cash Transfer Programme for Displaced Syrian Children in Lebanon (UNICEF and WFP): Impact Evaluation Endline Report, Innocenti Research Report (accessed 17 January 2022)

Denoeux, G. (1993) Urban Unrest in the Middle East: A Comparative Study of Informal Networks in Egypt, Iran, and Lebanon, New York: State University of New York (SUNY) Press

Desportes, I. (2019) 'Getting Relief to Marginalised Minorities: The Response to Cyclone Komen in 2015 in Myanmar', Journal of International Humanitarian Action 4.1: 7, DOI: 10.1186/s41018-019-0053-z (accessed 17 January 2022)

Dickson, K. and Bangpan, M. (2012) Providing Access to Economic Assets for Girls and Young Women in Low-and-Lower Middle-Income Countries: A Systematic Review of the Evidence, London: EPPICentre, Social Science Research Unit, Institute of Education, University of London

Dietrich, S. et al. (2017) Social Protection Investments, Human Capital, and Income Growth: Simulating the Returns to Social Cash Transfers in Uganda, UNU-Merit Working Paper \#2017-029, Maastricht: Maastricht University/United Nations University (accessed 18 January 2022)

Dominey-Howes, D.; Gorman-Murray, A. and McKinnon, S. (2014) 'Queering Disasters: On the Need to Account for LGBTI Experiences in Natural Disaster Contexts', Gender, Place \& Culture 21.7: 905-18, DOI: 10.1080/0966369X.2013.802673 (accessed 17 January 2022)

Doocy, S. and Tappis, H. (2017) Cash-Based Approaches in Humanitarian Emergencies: A Systematic Review, The Campbell Collaboration (accessed 17 January 2022)

Douma, N. and Hilhorst, D. (2012) Fond de Commerce? Sexual Violence Assistance in the Democratic Republic of Congo, Disaster Studies Occasional Paper 2, Wageningen University (accessed 17 January 2022)

Dunne, M.; Humphreys, S. and Szyp, C. (2021) Education and Work: Children's Lives in Rural Sub-Saharan Africa, ACHA Working Paper 9, Brighton: Action on Children's Harmful Work in African Agriculture, IDS, DOI: 10.19088/ACHA.2021.004 (accessed 17 January 2022)

ECHO (2013) The Use of Cash and Vouchers in Humanitarian Crises: DG ECHO Funding Guidelines, European Commission (accessed 17 January 2022)

Ecker, O.; Maystadt, J.-F. and Guo, Z. (2019) Can Unconditional Cash Transfers Mitigate the Impact of Civil Conflict on Acute Child Malnutrition in Yemen? Evidence from the National Social Protection Monitoring Survey, Cairo, Egypt: International Food Policy Research Institute (IFPRI) (accessed 17 January 2022)

Edge Effect (2020) 'Briefing Note: Impacts of COVID-19 on LGBTIQ+ People' (accessed 17 January 2022)

Edge Effect; ASC and APCOM (2018) Pride in the Humanitarian System, Bangkok 4-7 June 2018, Consultation Report (accessed 17 January 2022)

Edgell, A.B.; Grahn, S.; Lachapelle, J.; Lührmann, A. and Maerz, S.F. (2020) An Update on Pandemic Backsliding: Democracy Four Months After the Beginning of the Covid-19 Pandemic, Gothenburg: VDem Institute

Ezcurra, R. and Rodríguez-Pose, A. (2009) Does Decentralization Matter for Regional Disparities? A Cross-Country Analysis, SERC Discussion Papers 0025, Spatial Economics Research Centre, London School of Economics and Political Science (accessed 17 January 2022)

Fehrenbacher, A.E. and Patel, D. (2019) 'Translating the Theory of Intersectionality into Quantitative and Mixed Methods for Empirical Gender Transformative Research on Health', Culture, Health \& Sexuality 22.sup1: 145-60, DOI: 10.1080/13691058.2019.1671494 (accessed 17 January 2022)

Freccero, J. et al. (2019) 'Safer Cash in Conflict: Exploring Protection Risks and Barriers in Cash Programming for Internally Displaced Persons in Cameroon and Afghanistan', International Review of the Red Cross 101.911: 685-713, DOI: 10.1017/S1816383120000119

Garcia, M. (2012) It's All Our Fault! 10 Disasters the Gays Supposedly Caused, Advocate.com, 31 October (accessed 18 January 2022) 
Gender in Humanitarian Action Asia and the Pacific Working Group (2017) 'Integrating Gender into Humanitarian Action: Good Practices from Asia-Pacific 6", Gender in Humanitarian Action Asia and the Pacific Working Group (accessed 27 January 2022)

GHD (2003) '24 Principles and Good Practice of Humanitarian Donorship', Stockholm: Good Humanitarian Donorship Initiative (accessed 18 January 2022)

Gibbs, A.; Jacobson, J. and Kerr Wilson, A. (2017) 'A Global Comprehensive Review of Economic Interventions to Prevent Intimate Partner Violence and HIV Risk Behaviours', Global Health Action 10.sup2: 1290427, DOI: 10.1080/16549716.2017.1290427 (accessed 18 January 2022)

Gill, T. (2007) Making Things Worse: How 'Caste Blindness' in Indian Post-Tsunami Disaster Recovery has Exacerbated Vulnerability and Exclusion, Dalit Network Netherlands (DNN) (accessed 18 January 2022)

Gobierno de Colombia (2020) Jóvenes en Acción - Transferencias Condicionadas de Prosperidad Social, Prosperidad Social blog (accessed 16 March 2021)

Golooba-Mutebi, F. (2004) 'Reassessing Popular Participation in Uganda', Public Administration and Development 24.4: 289-304 (accessed 18 January 2022)

GPC Task Team on Cash for Protection (2020) Cash and Voucher Assistance for Protection: Taking Stock of Cash and Voucher Assistance to Achieve Protection Outcomes in the Protection Sector in Humanitarian Settings (accessed 18 January 2022)

Grabe, S. (2020) 'Research Methods in the Study of Intersectionality in Psychology: Examples Informed by a Decade of Collaborative Work With Majority World Women's Grassroots Activism', Frontiers in

Psychology 11 (accessed 18 January 2022)

Grace, D. (2014) Intersectionality-Informed Mixed Methods Research: A Primer, The Institute for Intersectionality Research \& Policy, SFU (accessed 18 January 2022)

Gressmann, W. (2016) From the Ground Up: Gender and Conflict Analysis in Yemen, Oxford: Oxfam (accessed 18 January 2022)

Haddad, T. (2020) 'Religious Welfare Organizations, Citizenship, and the State in Lebanon', Nonprofit Policy Forum 11.3: 20190040 (accessed 18 January 2022)

Hagen-Zanker, J. et al. (2017) The Impact of Cash Transfers on Women and Girls: A Summary of the Evidence, London: Overseas Development Institute (accessed 18 January 2022)

Handicap International (2015) Disability in Humanitarian Contexts: Views from Affected People and Field Organisations, France: Handicap International (accessed 18 January 2022)

Hankivsky, O. (ed) (2012) An Intersectionality-Based Policy Analysis Framework, Vancouver: Institute for Intersectionality Research and Policy, Simon Fraser University

Harvey, P. and Pavanello, S. (2018) Multi-Purpose Cash and Sectoral Outcomes: A Review of Evidence and Learning, Geneva: UNHCR (accessed 18 January 2022)

Heidari, S.; Ahumada, C. and Kurbanova, Z. (2020) 'Towards the Real-Time Inclusion of Sex- and AgeDisaggregated Data in Pandemic Responses', BMJ Global Health 5.10: e003848 (accessed 18 January 2022)

Hemingway, L. and Priestley, M. (2006) 'Natural Hazards, Human Vulnerability and Disabling Societies: A Disaster for Disabled People?", Review of Disability Studies: An International Journal 2.3 (accessed 18 January 2022)

Holden, J.; Lee, H.; Martineau-Searle, L. and Kett, M. (2019) Disability Inclusive Approaches to Humanitarian Programming: Summary of Available Evidence on Barriers and What Works, Disability Inclusion Helpdesk Research Report No. 9. London: Disability Inclusion Helpdesk (accessed 18 January 2022)

Holmes, R. (2009) 'Cash Transfers in Post-Conflict Contexts', Project Briefing No. 32, London: Overseas Development Institute (accessed 18 January 2022)

Holmes, R. and Jackson, A. (2007) Cash Transfers in Sierra Leone: Are They Appropriate, Affordable or Feasible?, London: Overseas Development Institute (accessed 18 January 2022) 
HRW (2019) 'Mozambique: Cyclone Victims Forced to Trade Sex for Food', Human Rights Watch, 25 April (accessed 18 January 2022)

Hussain, K. (2020) 'Transgender Community Fears Complete Lockdown Will Add More Miseries to Life', The Express Tribune, 22 March (accessed 27 January 2022)

IASC (2020) With Us \& For Us: Working With and For Young People in Humanitarian and Protracted Crises, UNICEF and Norwegian Refugee Council (NRC) for the Compact for Young People in Humanitarian Action (accessed 18 January 2022)

ICRC (2020) Covid-19: Inclusive Programming - Ensuring Assistance and Protection Addresses the Needs of Marginalized and At-Risk People, Geneva: International Committee of the Red Cross (accessed 18 January 2022)

International Gay and Lesbian Human Rights Commission (2011) The Impact of the Earthquake, and Relief and Recovery Programs on Haitian LGBT People, New York: International Gay and Lesbian Human Rights Commission (accessed 18 January 2022)

International Policy Centre for Inclusive Growth (2018) 'Non-Contributory Social Protection Through a Child and Equity Lens in Libya', Brasilia: International Policy Centre for Inclusive Growth (accessed 18 January 2022)

IRC (2016) Women's Protection and Livelihoods: Assistance to Central African Refugees and Chadian Returnees in Southern Chad - Program Evaluation Final Report, New York: International Rescue Committee (accessed 18 January 2022)

IRC; Save the Children and Catholic Relief Services (2017) Rapport Final du Programme: Valorisation de la Scolarisation de la Fille, (accessed 18 January 2022)

Jones, N. (2021) How to Maximise the Impact of Cash Transfers for Vulnerable Adolescents in Jordan, Amman: UNICEF Jordan (accessed 18 January 2022)

Jones, N.; Pincock, K. and Abu-Hamad, B. (2021) Adolescents in Humanitarian Crisis: Displacement, Gender and Social Inequalities, London: Routledge (accessed 18 January 2022)

Jones, N.; Pincock, K. and Yadete, W. (2021) 'We Are Not Accepted Here': Intersecting Vulnerabilities of Internally Displaced Adolescents in Ethiopia', in N. Jones, K. Pincock and B. Abu-Hamad (eds),

Adolescents in Humanitarian Crisis: Displacement, Gender and Social Inequalities, London: Routledge (accessed 18 January 2022)

Jones, N. et al. (2016) 'Transforming Cash Transfers: Citizens' Perspectives on the Politics of Programme Implementation', The Journal of Development Studies 52.8: 1207-24, DOI:

10.1080/00220388.2015.1134772 (accessed 18 January 2022)

Justino, P. (2014) Barriers to Education in Conflict-Affected Countries and Policy Opportunities, Paper commissioned for Fixing the Broken Promise of Education for All: Findings from the Global Initiative on Out-of-School Children (UIS/UNICEF, 2015), Montreal: UNESCO Institute for Statistics (UIS) (accessed 18 January 2022)

Kelly, L. (2019) Evidence on Social Inclusion Programming in Nigeria, K4D Helpdesk Report 690, Brighton, UK: Institute of Development Studies (accessed 18 January 2022)

Kidd, S. (2017) 'Social Exclusion and Access to Social Protection Schemes', Journal of Development Effectiveness 9.2: 212-44, DOI: 10.1080/19439342.2017.1305982 (accessed 18 January 2022)

Kidd, S. (2014) Social Exclusion and Access to Social Protection Schemes, Barton, Australia: Department of Foreign Affairs and Trade, Australian Government (accessed 18 January 2022)

Knight, K. (2017) Documents and Disasters: Can Proper ID Save the Lives of Transgender People in Emergencies?, HuffPost blog, 6 December (accessed 18 January 2022)

Lehrer, K. (2009) Gender Differences in Labour Market Participation During Conflict: Evidence from Displaced People's Camps in Northern Uganda (accessed 18 January 2022) 
Lokot, M. and Avakyan, Y. (2020) 'Intersectionality as a Lens to the COVID-19 Pandemic: Implications for Sexual and Reproductive Health in Development and Humanitarian Contexts', Sexual and Reproductive Health Matters 28.1: 1764748, DOI: 10.1080/26410397.2020.1764748 (accessed 18 January 2022)

Mahmood, S. (2017) Challenges of Children Born by ISIS Rape in Iraq, CERAH Working Paper, The Graduate Institute \& University of Genève

McAteer, J. (2020) Safe Programming in Design of Cash and Voucher Assistance - Lessons Learnt, Plan International (accessed 18 January 2022)

McGivern, V. and Bluestone, K. (2020) If Not Now, When? Keeping Promises to Older People Affected by Humanitarian Crises, London: HelpAge International (accessed 18 January 2022)

Merttens, F.; Sindou, E.; Attah, R. and Hearle, C. (2016) Evaluation of the Uganda Social Assistance Grants For Empowerment (SAGE) Programme, Impact After Two Years of Programme Operations 2012-2014 Final Report, Oxford: Oxford Policy Management (accessed 18 January 2022)

Molyneux, M.; Jones, W.N. and Samuels, F. (2016) 'Can Cash Transfer Programmes Have "Transformative" Effects?", The Journal of Development Studies 52.8: 1087-98, DOI:

10.1080/00220388.2015.1134781 (accessed 18 January 2022)

Moses (2013) 'The Rainbow Group in Mae La Camp', Forced Migration Review 42, (accessed 18 January 2022)

Narayan, D.; Patel, R.; Schafft, K.; Rademacher, A. and Koch-Schulte, S. (2000) Voices of the PoorCan Anyone Hear Us? New York: Oxford University Press for the World Bank (accessed 18 January 2022)

Neenan, J. (2017) Closing the Protection Gap for Children Born of War: Addressing Stigmatisation and the Intergenerational Impact of Sexual Violence in Conflict, London: LSE Centre for Women, Peace and Security (accessed 18 January 2022)

Nicolai, S. and Triplehorn, C. (2003) The Role of Education in Protecting Children in Conflict, HPN Paper 42, London: Overseas Development Institute/Humanitarian Practice Network, (accessed 18 January 2022)

Nightingale, K. (2013) Equality in Aid: Addressing Caste Discrimination in Humanitarian Response, International Dalit Solidarity Network (IDSN) (accessed 18 January 2022)

OHCHR (2020) 'Racial Discrimination in the Context of the COVID-19 Crisis', Topics in Focus, Racial Discrimination, 22 June, Office of the United Nations High Commissioner for Human Rights (accessed 18 January 2022)

Olanrewaju, F.O. et al. (2019) 'Insurgency and the Invisible Displaced Population in Nigeria: A Situational Analysis', SAGE Open 9.2, DOI:10.1177/2158244019846207 (accessed 18 January 2022)

Onyango, E.O. (2012) Manhood on the Margins: Failing to be a Man in Post-Conflict Northern Uganda, MICROCON Research Working Paper 68, Brighton: MICROCON (accessed 18 January 2022)

Özler, B. et al. (2020) 'Girl Empower - A Gender Transformative Mentoring and Cash Transfer Intervention to Promote Adolescent Wellbeing: Impact Findings From a Cluster-Randomized Controlled Trial in Liberia', SSM - Population Health 10: 100527 (accessed 18 January 2022)

PAHO (2020) 'Why Data Disaggregation Is Key During A Pandemic', Pan American Health Organization (accessed 18 January 2022)

Paulocanning (2011) In Pakistan's Floods, Transgender People 'Languishing Silently in Pain', LGBT Asylum News blog, 22 October (accessed 18 January 2022)

Pearce, E. (2015) “'Ask Us What We Need”: Operationalizing Guidance on Disability Inclusion in Refugee and Displaced Persons Programs', Disability and the Global South 2.1: 19

Pereznieto, P.; Magee, A. and Fyles, W.N. (2017) Mitigating Threats To Girls' Education In ConflictAffected Contexts: Current Practice, United Nations Girls' Education Initiative (accessed 18 January 2022) 
Pirola, A.; Mbeng, B.T. and Jenkins, M. (2018) 'Results and Lessons Learned from WFP's Efforts to Support Adolescent Girls in Niger', Field Exchange 58: 2 (accessed 17 January 2022)

Plan International (2020) Cash and Voucher Assistance for Adolescents: An Evidence Review of How Cash and Voucher Assistance Can Achieve Outcomes for Adolescents in Humanitarian Settings,

Woking: Plan International and Women's Refugee Commission (accessed 18 January 2022)

Plan International (2018) Adolescent Girls in Crisis: Voices from South Sudan, Woking: Plan International (accessed 18 January 2022)

Plan International and WRC (2020) WRC Assessments of Plan International's Adolescent-Focused Cash and Voucher Assistance Projects: Synopsis of Case Studies in Egypt and Central African Republic, Woking: Plan International and Women's Refugee Commission (accessed 18 January 2022)

Potts, A.; Fattal, L.; Hedge, E.; Hallak, F. and Reese, A. (2020a) Empowered Aid: Participatory Action Research with Refugee Women \& Girls to Better Prevent Sexual Exploitation and Abuse-Lebanon Results Report, Washington DC and Lebanon: The George Washington University and CARE International (accessed 19 January 2022)

Potts, A.; Kolli, H.; Hedge, E. and Ullman, C. (2020b) Empowered Aid: Participatory Action Research with Refugee Women \& Girls to Better Prevent Sexual Exploitation and Abuse-Uganda Results Report, Washington DC and Kampala: The George Washington University and IRC (accessed 19 January 2022)

Presler-Marshall, E. and Jones, N. (2018) The Devil is in the Detail: Why a Gender- and AdolescentSpecific Lens is Essential to Accelerate Progress in Eradicating Child Exploitation, London: Gender and Adolescence: Global Evidence (accessed 19 January 2022)

Presler-Marshall, E.; Jones, N. and Odeh, K.B. (2020) "“Even though I Am Blind, I Am Still Human!": The Neglect of Adolescents with Disabilities' Human Rights in Conflict-Affected Contexts', Child Indicators Research 13.2: 513-31 (accessed 19 January 2022)

Rahman, Z. (2017) Irresponsible Data? The Risks of Registering the Rohingya, The New Humanitarian blog, 23 October (accessed 19 January 2022)

Rauf, W. (2016) Empowering Women and Girls Affected by Crisis: CARE's Progress Towards Achieving Gender Equality in Humanitarian Programming, Geneva: CARE International (accessed 27 January 2022)

RFA's Myanmar Service (2014) 'Myanmar Will Not Recognize Rohingyas on Upcoming Census', Radio Free Asia, 13 March (accessed 19 January 2022)

Robinson, A.; Marella, M. and Logam, L. (2020) Gap Analysis: The Inclusion of People With Disability and Older People in Humanitarian Response, London: Elrha (accessed 19 January 2022)

Rodriguez, J. (2018) 'Intersectionality and Qualitative Research', in C. Cassell, A.L. Cunliffe and G. Grandy (eds), The Sage Handbook of Qualitative Business and Management Research Methods, SAGE Publications Ltd (accessed 27 January 2022)

Roelen, K. (2020) 'Receiving Social Assistance in Low- and Middle-Income Countries: Negating Shame or Producing Stigma?', Journal of Social Policy 49.4: 705-23, DOI:10.1017/S0047279419000709 (accessed 27 January 2022)

Roelen, K. and Shelmerdine, H. (2014) Researching the Linkages Between Social Protection and Children's Care in Rwanda, Brighton: Institute of Development Studies (accessed 19 January 2022)

Rohwerder, B. (2022) Inclusion of Marginalised Groups in Social Assistance in Crises, BASIC Research Theme Brief, Brighton: Institute of Development Studies, DOI: 10.19088/BASIC.2022.023

Rohwerder, B. (2020) Social Impacts and Responses Related to Covid-19 in Low- and Middle-income Countries, K4D Emerging Issues Report 35, Brighton: Institute of Development Studies (accessed 19 January 2022)

Rohwerder, B. (2017) Disability Inclusive Humanitarian Response, Humanitarian Learning Centre Operational Practice Paper 1, Brighton: HLC (accessed 19 January 2022)

Rohwerder, B. (2016) Women and Girls With Disabilities in Conflict and Crises, K4D Helpdesk Report, Brighton: Institute of Development Studies (accessed 19 January 2022) 
Rumbach, J. and Knight, K. (2014) 'Sexual and Gender Minorities in Humanitarian Emergencies', in L.W. Roeder (ed.), Issues of Gender and Sexual Orientation in Humanitarian Emergencies, Humanitarian Solutions in the 21st Century, Cham: Springer International Publishing (accessed 19 January 2022)

Sadat, A. (2018) Inclusion Factsheet - Shelter/NFI/CCCM, Yemen 2018, Handicap International Humanity \& Inclusion (accessed 19 January 2022)

Salti, N. and Chaaban, J. (2010) 'The Role of Sectarianism in the Allocation of Public Expenditure in Postwar Lebanon', International Journal of Middle East Studies 42.4: 637-55, DOI:

10.1017/S0020743810000851 (accessed 19 January 2022)

Sheppard, P.; Polack, S. and McGivern, M. (2018) Missing Millions: How Older People With Disabilities are Excluded From Humanitarian Response, London: HelpAge International (accessed 13 January 2022)

Sida (2010) Poverty and Sexuality: What are the Connections? Overview and Literature Review, Stockholm: Swedish International Development Cooperation Agency (accessed 19 January 2022)

Silva, K.T.; Sivapragasam, P.P.; Thanges, P.; International Dalit Solidarity Network, and Indian Institute of Dalit Studies (eds) (2009) Casteless or Caste-Blind? Dynamics of Concealed Caste Discrimination, Social Exclusion, and Protest in Sri Lanka, Copenhagen and New Delhi : Indian Institute of Dalit Studies; Colombo: International Dalit Solidarity Network; Kumaran Book House

Simon, C.A. (2019) The Effect of Cash-Based Interventions on Gender Outcomes in Development and Humanitarian Settings, New York: UN Women (accessed 19 January 2022)

Simon, C.A. (2018) Setting the Stage: What We Know (and Don't Know) About the Effects of CashBased Interventions on Gender Outcomes in Humanitarian Settings, New York: UN Women (accessed 13 January 2022)

Slater, R. (2022) Humanitarian and Social Protection Approaches to Inclusion: Knowledge Gaps and Implications for Working in the Humanitarian-Social Protection Nexus, BASIC Research Working Paper 16, Brighton: Institute of Development Studies, DOI: 10.19088/BASIC.2022.016

Slater, R. and Sabates-Wheeler, R. (2021) 'Defining Social Assistance for the BASIC Research Programme: Internal Guidance Note', unpublished report, BASIC Research

Sphere Association (2018) The Sphere Handbook: Humanitarian Charter and Minimum Standards in Humanitarian Response, Sphere Association (accessed 19 January 2022)

Stark, L. and Ager, A. (2011) 'A Systematic Review of Prevalence Studies of Gender-Based Violence in Complex Emergencies', Trauma, Violence \& Abuse 12.3: 127-34 (accessed 19 January 2022)

Sumberg, J. and Sabates-Wheeler, R. (2020) 'Children's Work in African Agriculture: Time for a Rethink', Outlook on Agriculture, 49.2: 99-102 (accessed 19 January 2022)

Szyp, C. and Sabates-Wheeler, R. (2019) Cash Transfer Programming: Trends and Patterns Among Irish Aid's Partners, IDS Working Paper 532, Brighton: Institute of Development Studies (accessed 19 January 2022)

Tafere, Y. and Woldehanna, T. (2012) Beyond Food Security: Transforming the Productive Safety Net Programme in Ethiopia for the Well-Being of Children, Oxford: Young Lives, Oxford Department of International Development

Thomas, E. (2018) 'Tagged, Tracked and in Danger: How the Rohingya Got Caught in the UN's Risky Biometric Database', Wired UK, 12 March (accessed 19 January 2022)

TRANSFORM (2020) Shock Responsive Social Protection - Manual for Leadership and Transformation Curriculum on Building and Managing Social Protection Floors in Africa, TRANSFORM (accessed 27 January 2022)

Türk, V. (2013) 'Ensuring Protection to LGBTI Persons of Concern', International Journal of Refugee Law 25.1: 120-29, (accessed 19 January 2022)

UK Aid Direct (2017) 'Defining Marginalised; DFID's Leave No One Behind Agenda', Mannion Daniels, Fund Manager for UK Aid Direct (accessed 18 January 2022) 
UN (2021) How to Design Disability-Inclusive Social Protection, Thailand: United Nations Economic and Social Commission for Asia and the Pacific (accessed 19 January 2022)

UNDESA (2018) Promoting Inclusion Through Social Protection: Report on the World Social Situation 2018, New York: United Nations Department of Economic and Social Affairs (accessed 27 January 2022)

UNHCR (2021) Working With Older Persons in Forced Displacement, Need to Know Guidance 5, Geneva: UNHCR (accessed 27 January 2022)

UNHCR (2018) Cash Assistance and Gender: Key Considerations and Learning, Geneva: The UN Refugee Agency (accessed 19 January 2022)

UNHCR; UNICEF and WFP (2017) Vulnerability Assessment Report of Syrian Refugees in Lebanon, VASYR 2017, Lebanon: The UN Refugee Agency, United Nations Children's Fund and World Food

Programme (accessed 19 January 2022)

UNICEF (2020) Integrated Model of Social and Economic Assistance and Empowerment (IMSEA), UNICEF Yemen Country Office (accessed 19 January 2022)

Vu, A. et al. (2014) 'The Prevalence of Sexual Violence Among Female Refugees in Complex Humanitarian Emergencies: A Systematic Review and Meta-Analysis', PLoS Currents 6 (accessed 19 January 2022)

Wilkinson, O. (2018) "'Faith Can Come In, But Not Religion": Secularity and its Effects on the Disaster Response to Typhoon Haiyan', Disasters 42.3: 459-74 (accessed 19 January 2022)

Women's Refugee Commission (2014) Strong Girls, Powerful Women: Program Planning and Design for Adolescent Girls in Humanitarian Settings, New York: Women's Refugee Commission

Women's Refugee Commission and Adeso (2018) Mainstreaming Gender-Based Violence Considerations In Cash-Based Interventions: A Case Study From Lower Juba, Somalia, New York:

Women's Refugee Commission and African Development Solutions (accessed 19 January 2022)

World Vision (2020) Covid-19 Aftershocks: A Perfect Storm - Millions More Children at Risk of Violence Under Lockdown and Into the 'New Normal', World Vision (accessed 19 January 2022)

World Vision Iraq (2018) 'Understanding Cash-based Programming and Protection In Northern Region of Iraq', World Vision (accessed 27 January 2022)

Zoungrana, H.P. (2017) Endogenous Protection Practices for Children on the Move During Emergencies in Gao and Timbuktu, Mali, London: International Institute for Environment and Development (accessed 19 January 2022) 


\section{Acknowledgements and Disclaimer}

This document was developed by the Better Assistance in Crises (BASIC) Research programme. BASIC is implemented by the Institute of Development Studies (IDS), the University of Sussex and the Centre for International Development and Training, funded by UKAid from the UK government. The views expressed in this document are entirely those of the authors and do not necessarily represent views or policies of the UK governments official policies.

The authors would like to thank Rachel Slater, Jeremy Lind, Keetie Roelen, Nicola Jones, Harri Lee, Tom Palmer, Roopa Hinton, and Ciara Silke for their reviews and helpful comments on earlier drafts of this paper.

(C) IDS copyright 2022. Copyright in the typographical arrangement and design rests with IDS.

This publication (excluding the logos) may be reproduced free of charge in any format or medium, provided that it is reproduced accurately and not used in a misleading context. The material must be acknowledged as IDS copyright with the title and source of the publication specified.

Published by IDS.

\section{Suggested citation}

Rohweder, B. and Szyp, C. (2022) The Risks and Outcomes of Getting Help for Marginalised People: Navigating Access to Social Assistance in Crises, BASIC Research Working Paper 7, Brighton: Institute of Development Studies, DOI: 10.19088/BASIC.2022.007 